\title{
PATHOLOGICAL RESEARCHES
}

\section{INTO THE \\ DISEASES OF THE EAR.}

BY JOSEPH TOYNBEE, F.R.S.,

FRLLOW OF THE ROYAL COLLEGE OF SURGEONS IN ENGLAND, AND SURGEON TO THE ST. GEORGE'S AND ST. JAMES'S GENERAL DISPENSARY, LONDON.

Received Jan. 9th.--Read Feb. 13th, 1849.

Since the publication in the Medico-Chirurgical Transactions of my two former papers, on the Pathology of the Ear, ${ }^{*}$ further research has enabled me to arrive at certain results, which it is hoped will not be deemed uninteresting to the profession.

The dissections on which the observations contained in this communication are based, amount to 915 ; and may be thus classified :

1. Ears of persons known to be deaf. . . . 184

2. Ears of persons supposed to be deaf . . . 70

3. Ears in the stage of incipient deafness . . . 358

4. Ears in a healthy state. . . . . . 303

Total . . . . . . . $\overline{915}$

The first class of cases, though including some instances hereafter specified, where the degree of deafness was but slight, comprises none in which a decided diminution of the power of hearing had not been perceptible during life.

The second class of cases embraces those where, though the information was defective as to the state of hearing in the life-time of the parties, such extensive traces of disease were

* Volumes XXIV, 1841, and XXVI, 1843. The results of the one hundred and twenty dissections described in these two papers have been included in the subjoined tables. 
found in essential parts of the auditory organ, as to leave little doubt that deafness had existed. In the absence, however, of positive information, they are classed as cases of supposed or probable deafness.

The third class of cases exhibits those wherein there was a decided pathological condition of the organ, though probably not to the extent which would induce a very perceptible degree of deafness. These I have termed cases of incipient deafness.

It will doubtless excite some astonishment that, in so large a number as 915 dissections, so small a proportion as about one third of the ears should have been found in a perfectly natural state. At first view this might seem to arise from the specimens having, many of them, been supplied from hospitals, infirmaries, and other public institutions, and consequently liable to have been affected, as the result of the various diseases under which the parties might have laboured, and also from the circumstance of my having been kindly furnished by some of my professional friends with special cases, whose diseased state had, during life, attracted their attention. To those, however, who have given the subject much consideration, and who are aware of the widespread prevalence of deafness, in its varying degrees, among all classes of society, the dissections will not, perhaps, be thought to exhibit any unusual proportion of diseased to healthy specimens.

In the accompanying Tables it has been my endeavour to give the leading features of the several dissections in as concise a form as possible. In the first and second class of cases, however, it seemed indispensable to set forth, in succinct detail, the relative pathological conditions presented by different parts of the organ, as also the sex and age of the patient, and the cause of death. The third class of cases, those of incipient deafness, admitted of briefer treatment, and only the general result of their pathological state is exhibited; but it will give me great pleasure to afford, to any member of the profession, fuller information from the original notes of the dissections. 
The last of the tables is an abstract statement, intended to show at a glance the pathological condition of the 612 ears included in the preceding classes.

Although I am fully sensible that it would as yet be premature to attempt to deduce any very extensive general conclusions as to the causes of deafness, and the nature of diseases of the ear, from the dissections now brought under the notice of the profession-and each day's experience leads me to infer that little is but yet known, compared with what future investigation may bring to light-yet there are certain observations, even at the present stage of inquiry into the subject, which are not devoid of professional interest, and which I may venture to make with the more confidence, from the fact that several dissections conducted by me, since the tables were framed, are singularly confirmative of the conclusions arrived at.

\section{MEMBRANA TYMPANI.}

In the cases of deafness, the membrana tympani will be observed to have been, in nearly one sixth of the dissections, whiter and thicker than is natural. As this appearance depends generally upon a thickened condition of the mucous membrane lining the inner surface of the tympanic membrane, while the external surface remains smooth and shiny, this feature becomes of great importance to the medical practitioner, as it affords him, during life, an indication of the state of the cavity of the tympanum.

Another frequent and highly interesting pathological condition of the membrana tympani is that in which it adheres by its inner surface to the promontory and the ossicula, or establishes a connexion with them through the agency of bands of adhesion. In the former state, the membrana tympani is necessarily very concave externally, and this concavity is readily distinguishable during life; in the latter, the membrane is only occasionally concave. The adhesion in both instances is so firm, as often to equal in strength the fibrous texture of the tympanic membrane itself. The latter 
membrane is also much more tense than natural, and its power of vibration considerably diminished; in many instances, indeed, the tension is so great as to render it impassive to the loudest sounds.

In the formation of the above conditions, the adhesions are produced in the same way as those which will soon be alluded to as connecting the ossicula; but the adherence of the membrana tympani to the promontory grows out of the inflammation of the former membrane, during and subsequent to which, it and the tensor tympani muscle become very relaxed, the tympanic membrane falls inwards, and comes into contact with the mucous membrane covering the surface of the promontory. The latter also, in some cases, is so thickened as to touch and adhere to the healthy membrana tympani. During life I have seen it thick enough to protrude into the meatus, through an orifice in the tympanic membrane.

The proportion of specimens in those classed as deaf, where the membrana tympani appears to have been partially or completely destroyed, is larger, in my opinion, than among the cases occurring in practice, and may be accounted for from the greater attention which the existence of so very palpable a lesion would naturally excite. Although in these cases the sense of hearing was blunted, in many instances it was not so affected as to cause inconvenience in the ordinary intercourse of life. I may state, indeed, from a careful study of cases, some of which are now under my care, that the entire absence of the membrana tympani, provided no other disease of the organ of hearing coexists, is frequently but a trifling impediment to the perception of sounds.

\section{TYMPANIC CAVITY.}

A glance at the tables will show that the part of the organ of hearing which is the most frequent seat of disease is the cavity of the tympanum, and that, as described in my former papers, the peculiar pathological condition which characterises by far the greater number of cases, is a 
thickened state of the mucous membrane lining that cavity. This membrane is found to vary from that natural state of fine expansion, which renders its presence on the surface of the bones scarcely perceptible, to a degree of thickness which nearly fills the cavity, and completely buries the ossicula. It was thicker than natural in not less than 98 out of the 184 dissections of deaf persons. And it is instructive to compare these numbers with the proportion of only 19 out of 184 in which there was a collection of mucus, since the latter affection has hitherto been generally regarded as one of the most fertile sources of deafness.

The most common contents of the tympanic cavity are mucus, purulent discharges, and scrofulous matter, which correspond with the three diseases, colds, scarlet fever, and scrofula, from which deafness so frequently results.

A pathological condition of great frequency in the tympanic cavity is the formation of bands of adhesion connecting the ossicula with each other, and with the walls of the tympanum. In 42 of the 184 dissections of deaf ears these adhesions were traced, and they were present in 123 of the 358 dissections classed as those of incipient deafness, or in the large proportions of $\frac{1}{4}$ and $\frac{1}{3}$ respectively. By far the most usual position of these bands of adhesion is between the stapes and the promontory, the former bone being frequently entirely concealed by them. Often their tension and firmness are so great as to prevent any movement of the stapes, while in many instances they press it towards the cavity of the vestibule, as formerly remarked. It would appear highly probable that the pressure exerted on the membranous labyrinth by these adhesions may be one cause of the singing and other sounds so commonly com. plained of by deaf persons.

The bands of adhesion sometimes arise from the effusion of lymph, which is occasionally observed; but more frequently, perhaps, from the circumstance that, when the membrane is much thickened, the portions of it which are in contact become adherent, so that when the body of the membrane subsides to its natural state, the points of con- 
tact remain in cohesion, and the neighbouring parts are drawn into bands. The structure of the bands is firm, and very similar to that of the mucous membrane itself.

One of the most interesting conditions in the pathology of deafness is presented by the anchylosis of the base of the stapes to the margin of the fenestra ovalis, of which the specimens afford 16 complete and 10 partial instances. Sometimes this change consists of simple ossification of the membrane connecting the stapes with the margin of the fenestra ovalis; occasionally the base is considerably enlarged, and projects into the cavity of the vestibule; while in other instances it is surrounded by a deposit of osseous particles. My attention has also been very recently drawn to another condition of the stapes, which consists in its attachment to the circumference of the fenestra ovalis more firmly than is natural, a circumstance which is owing to the solidification of the membrane surrounding its base. Its occurrence is by no means infrequent.

The result of the examination of the Eustachian tube is deserving of particular attention. Of the whole 612 dissections of diseased ears, only 21 cases disclosed any traces of disease of this portion of the ear, a result, however, which agrees with my experience in cases of deafness.* Rarely indeed has it happened, when examining the ear with the otoscope, $\uparrow$ during a forcible expiration with closed nostrils, that the air could not be distinctly heard to enter the tympanic cavitics, though the nature of the sounds were modified by the internal condition of the cavity. While, to say the least, little or no good generally results from the use of

* It is right I should here state, that the trumpet-shaped extremity of the Eustachian tube was frequently not included in the parts removed for dissection. I am, therefore, unable to speak decidedly respecting its condition. It is, however, probable that, when the narrow portion of the tube was healthy and free from obstruction, the largely-dilated orifice which is acted upon so continually by the muscles of the palate, was also healthy.

$\dagger$ An elastic tube, about eighteen inches in length, tipped with ivory at both ends, one extremity of which is inserted into the external meatus of the patient, and the other into that of the medical man. 
the Eustachian catheter, the failure of the operation for puncturing the membrana tympani affords a striking proof, from daily practice, that deafness seldom depends upon obstruction of the Eustachian tubes.

It is singular that another theory of the cause of deafness, which made it to depend upon disease of the internal ear, receives no countenance from these dissections. Even in the few cases, 21 in number, where the labyrinth exhibited disease, that disease was, in nearly every instance, found to be propagated from the middle ear. It may indeed be added, that disease originating in the cavities which contain the expansion of the auditory nerve, or in their contents, is a phenomenon of very rare occurrence.*

The fact of a thickened or otherwise deranged state of the mucous membrane lining the tympanic cavity being one of the most common pathological conditions of the organ of hearing, is the broadest general result of the dissections; and as cases carefully examined, noted and studied as they have arisen in practice, lead to the same conclusion, I have little hesitation in stating disease of that membrane to be the most usual cause of deafness. What are the history and symptoms of the great majority of cases of deafness unattended by discharge? Cold has been caught, uneasiness has been felt, renewed attacks of cold $\dagger$ have added to the severity of the symptoms; advice is at length sought, and examination shows the external meatus deprived of cerumen, and frequently deficient in natural sensibility, while, towards the membrana tympani, its appearance is red and smooth; the membrana tympani is entire, its surface shines, but it is

* In some dissections, especially those from deaf persons where adequate causes of deafness were found in the tympanic cavity, for the sake of preserving the diseased parts, the internal ear was not examined.

$\dagger$ Disease once commenced is modified by many slight and, commonly, little regarded circumstances, - as going from a warm room into the cold air, indulgence even in a glass or two of wine, after a meal, \&c.; perspiration from active exercise gives temporary relief; distension of the tympanum with air either relieves or aggravates it; and the sounds so often complained of become louder under the influence of some of these circumstances. 
hazy, opaque, or as white as parchment, and consequently the handle of the malleus may be discerned with varying degrees of distinctness, or cease to be visible at all. Upon a forcible expiration, with closed nostrils, the air, by means of the otoscope, can almost always be heard to enter the tympanum, not gradually, however, as when the organ is healthy, but with a puffing, bubbling, or cracking sound, as though impeded in its progress.

It is not my intention, in the present communication, to enter into the detail of the curative measures which the various affections resulting in deafness might seem to indicate, but there are two considerations to which $I$ would direct the attention of the profession. The first is, the large number of cases of incipient disease, and their slow and imperceptible progress, which would reasonably lead us to hope that, by judicious treatment at an early period, the disease might be arrested in its progress, and a permanent cure effected. The other, that my own experience has shown me, that a careful perseverance in the course of remedial measures, which the pathological condition seemed to prescribe, has been attended with an almost unhoped-for success, and would amply justify the expectation, that if a rational mode of treatment, based on careful examination and under intelligent medical guidance, be pursued, the beneficial results in the relief of a disease, in which the moral suffering far exceeds the physical, will be abundantly manifest, and the profession itself be ultimately rescued from the opprobrium which justly attaches to imperfect diagnosis, and consequent empirical measures.

In conclusion, I cannot refrain from subjoining a few remarks on the intimate and important relation which the pathological condition of the ear bears to derangements in other organs. In one third of the dissections, for instance, the upper wall of the tympanum was so attenuated, that the mucous membrane was only separated from the dura mater by a perfectly translucent layer of bone. The upper wall of the tympanum, in 54 other dissections, was imperfect, and 
its mucous membrane was actually in contact with the dura mater. In 22 dissections, the lower wall of the tympanum was defective, and the mucous membrane was impinging on the internal jugular vein. The osseous lamina, separating the carotid canal from the tympanic cavity, is not unfrequently so thin as to be diaphanous; and the canal of the portio dura nerve, in its passage. through the tympanic cavity, is often imperfect enough to allow of the mucous membrane coming in contact with that nerve. The mastoid cells, again, are frequently found separated from the lateral sinus by a layer of bone of translucent thinness. Sometimes the osseous floor of the external meatus is deficient, being completed by the jugular vein; while its anterior wall is in many cases thin, and in parts so defective, as to bring the membranous meatus in close contiguity with the articulation of the lower jaw.

Numerous cases of disease, propagated from the ear to the brain and the other important organs alluded to, have fallen under my notice, and no very long time will, I trust; elapse before they are prepared, with the dissections, for submission to the profession. For the present I shall confine myself to stating that among these dissections there are instances in which disease has spread,-from the tympanum, upwards, causing inflammation and suppuration of the dura mater, with abscess in the middle lobe of the cerebrum; from the tympanum, below, producing disease of the jugular vein; from the mastoid cells, posteriorly, giving rise to suppuration of the lateral sinus, and diseases of the cerebellum; from the tympanum anteriorly, causing contraction, and almost entire obliteration of the carotid canal, and disease of the internal carotid artery. There are other instances where paralysis of the portio dura nerve has ensued from the pressure upon it of the thick mucous membrane of the cavity of the tympanum; and lastly, where inflammation of the articulation of the lower jaw proceeded to the extent of causing the mouth to remain for some time closed, in consequence of disease being continued to it from the anterior wall of the meatus. 
It will readily be conceived that I must be greatly indebted to many medical friends for valuable assistance in procuring specimens. To Mr. Crosse of Norwich, Mr. Ceeley of Aylesbury, Mr. Napper of Guildford, Mr. Greig of Bristol, for contributions from the country; - and to my colleague, Dr. Blakely Brown; Mr. Hewitt, assistant-surgeon of St. George's Hospital; Mr. Henry James Johnson, formerly assistant-surgeon to the same institution; Mr. Avery, surgeon to the Charing Cross Hospital ; Dr. Boyd, formerly resident physician to the St. Marylebone Infirmary, and to Dr. Allen, his successor; to Dr. Goodfellow, formerly resident physician to the London Fever Hospital, and to Dr. Sankey his successor; to Mr. Marston, resident medical officer of the Smallpox Hospital, Dr. Merriman jun., Dr. Edward Ormerod, Mr. Farish and Mr. Obre, of London, my sincere thanks are due; and $I$ beg to assure those gentlemen and other members of the profession, that for any opportunities they may afford me of further investigation $I$ shall feel most grateful. 
DISEASES OF THE EAR.

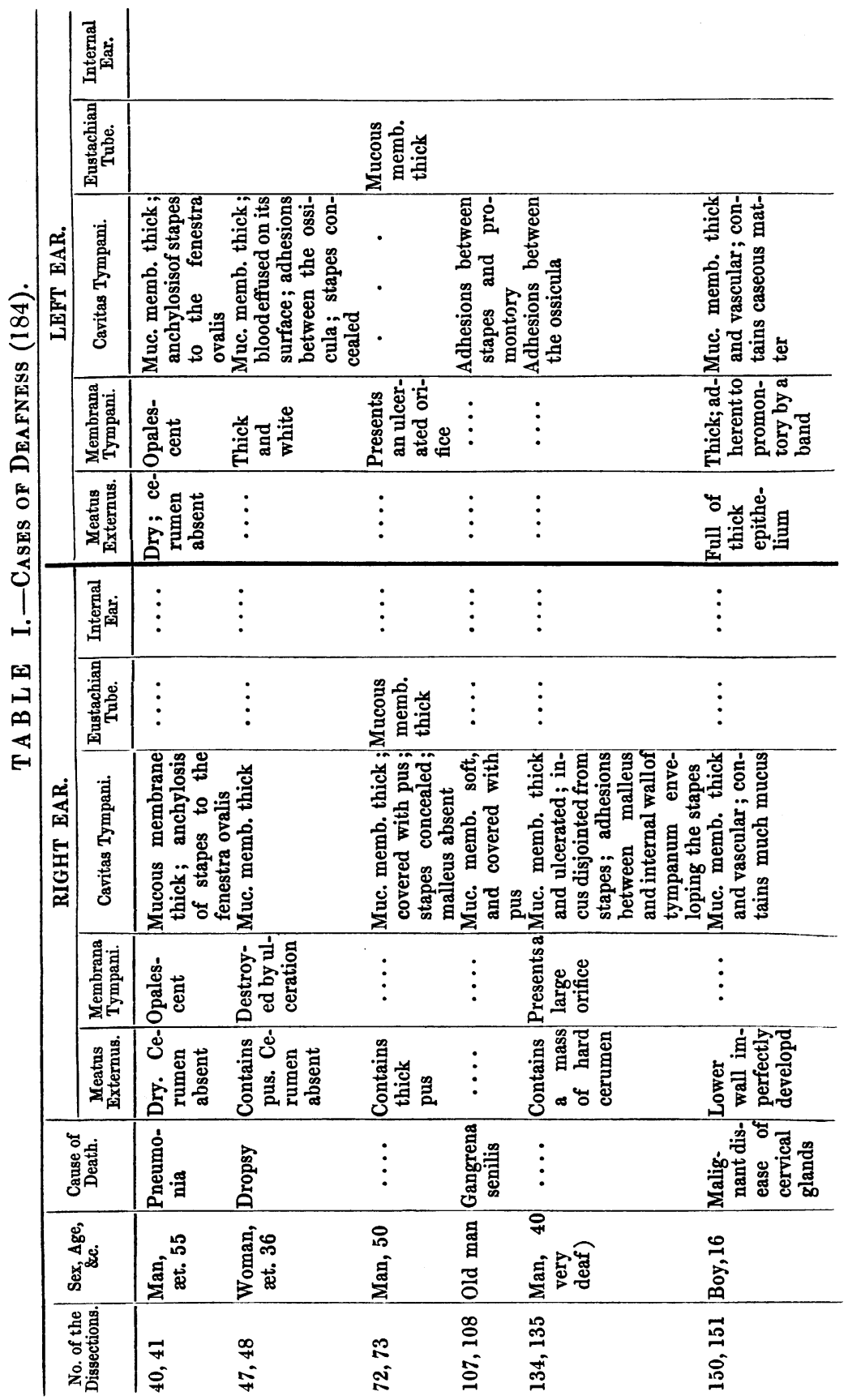




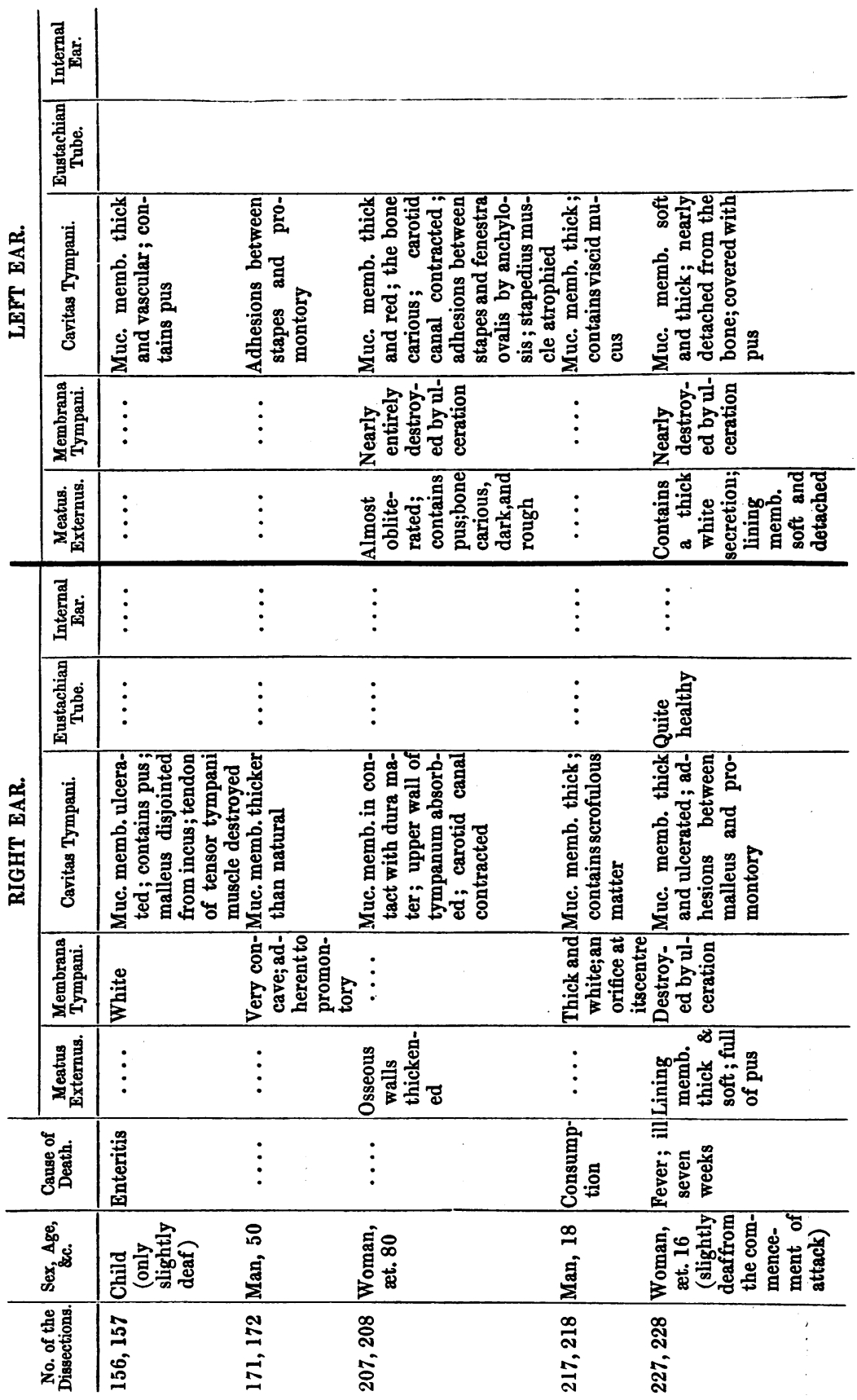




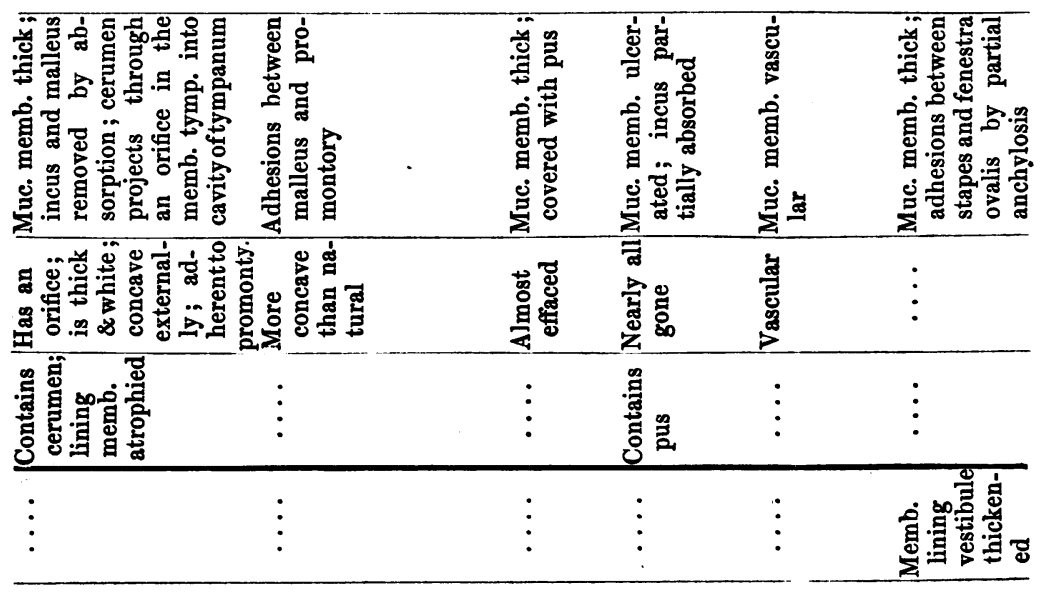

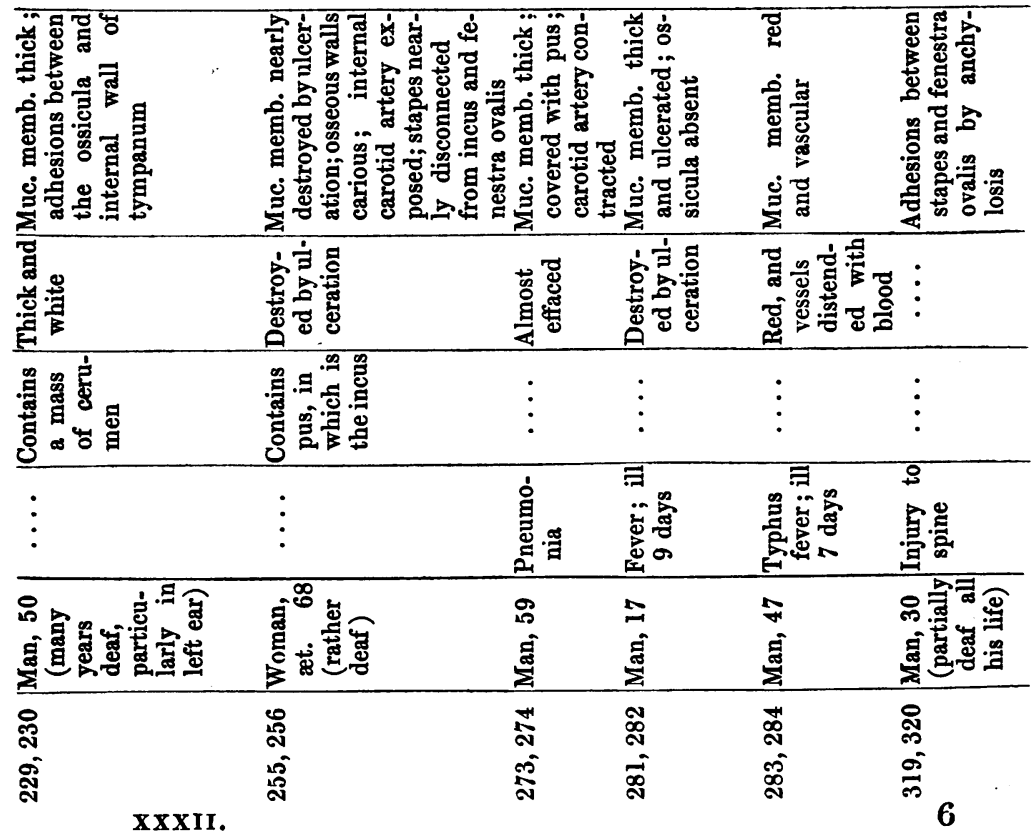




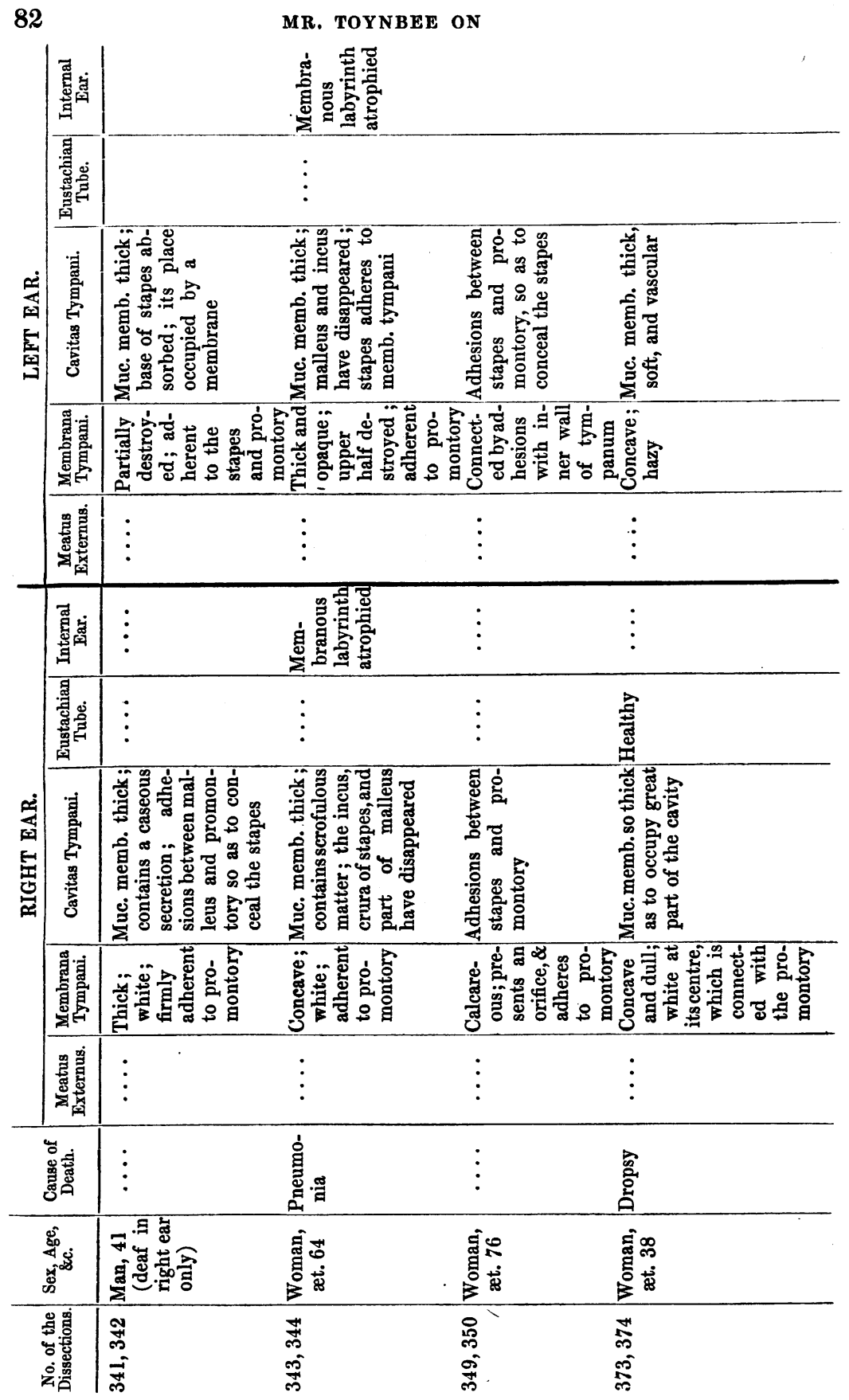




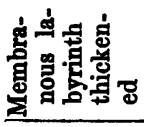
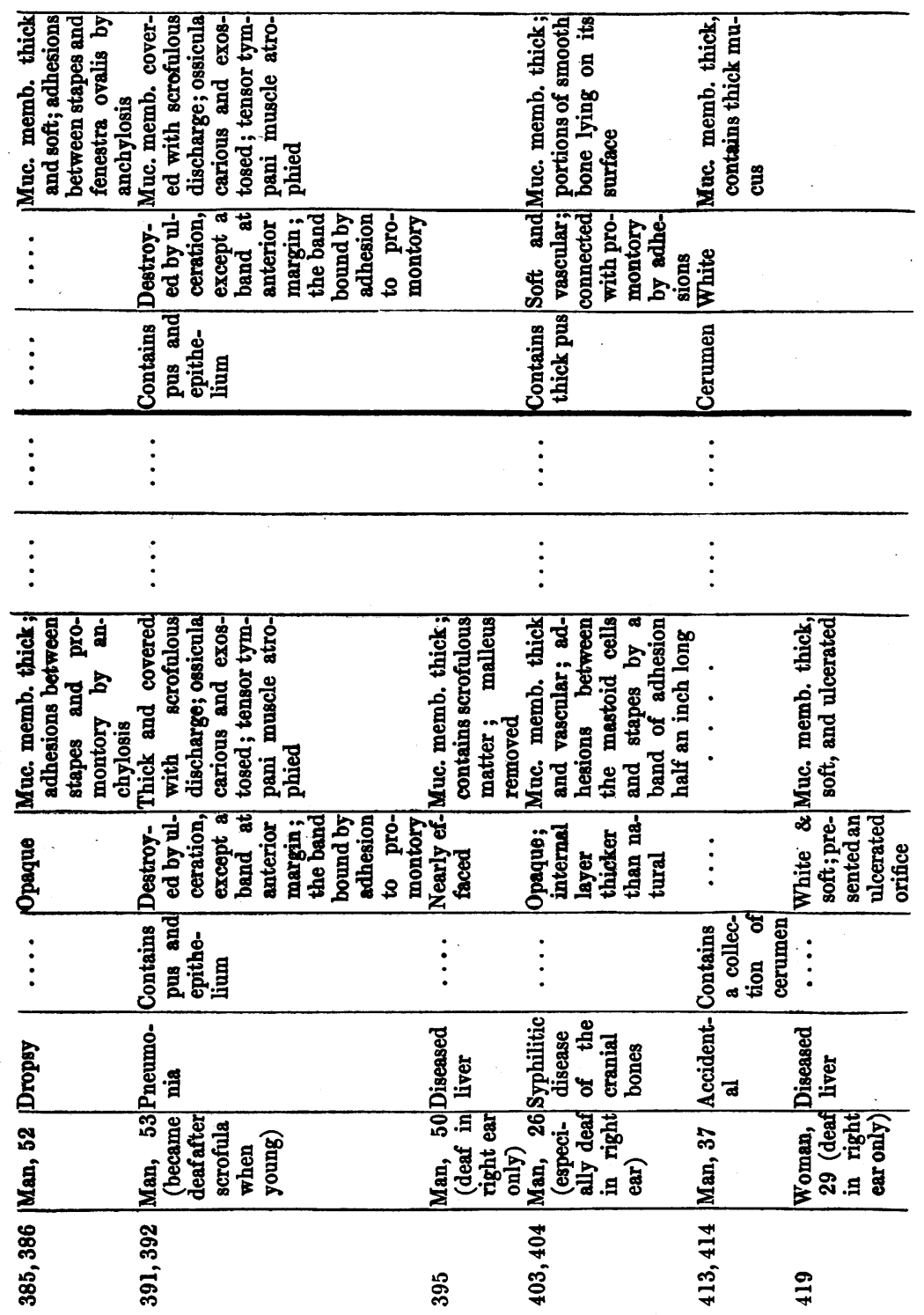


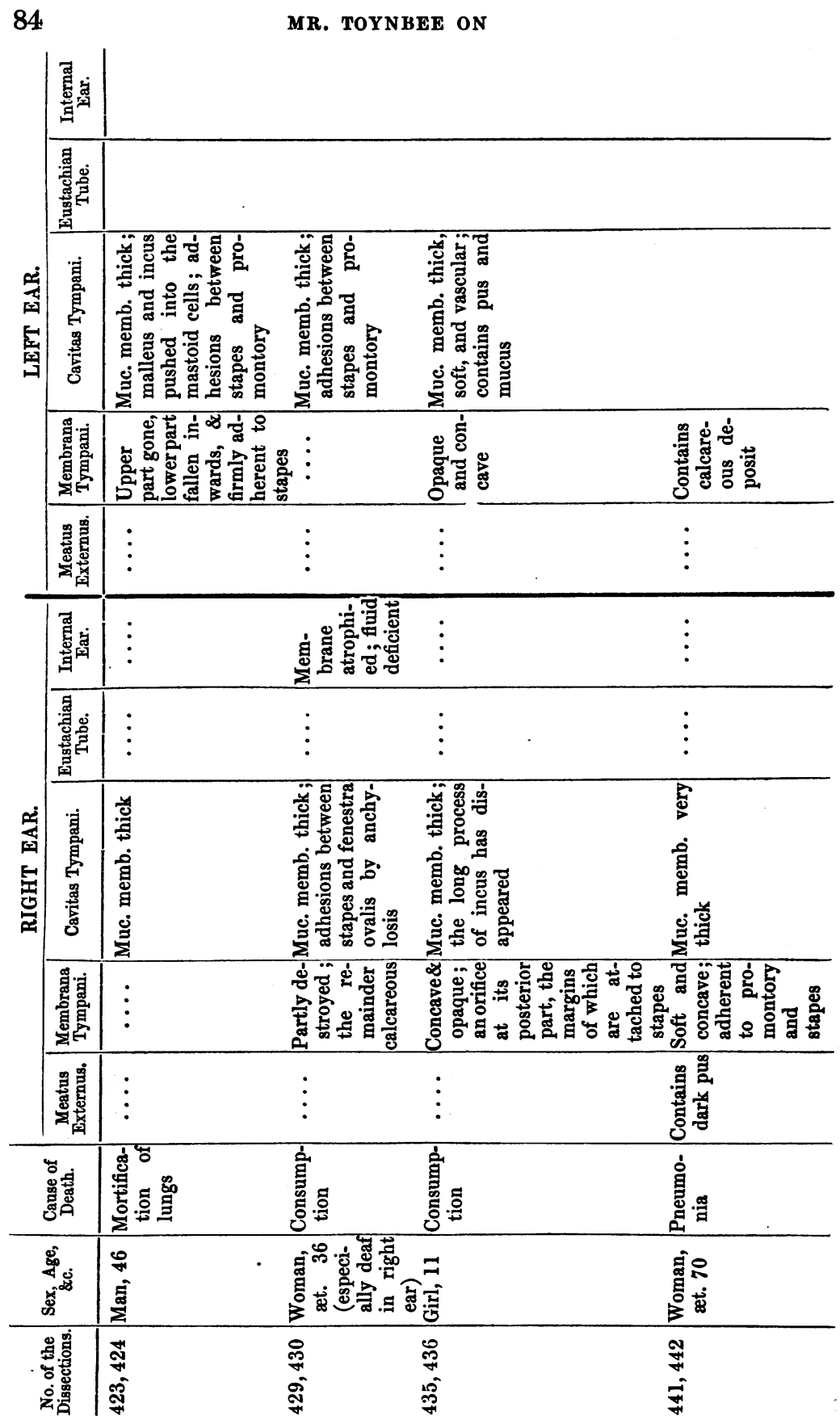


DISEASES OF THE EAR.

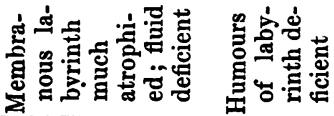

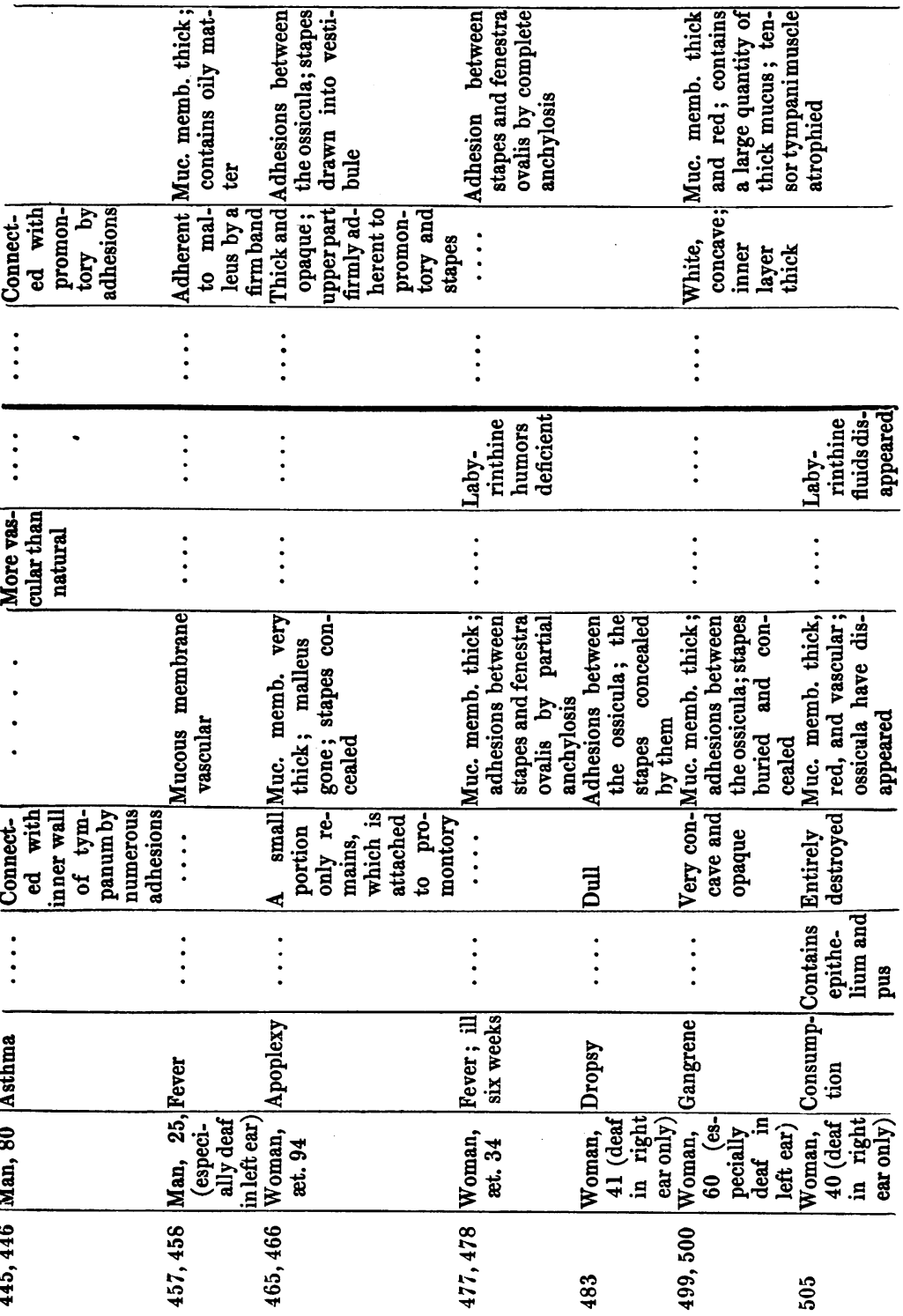




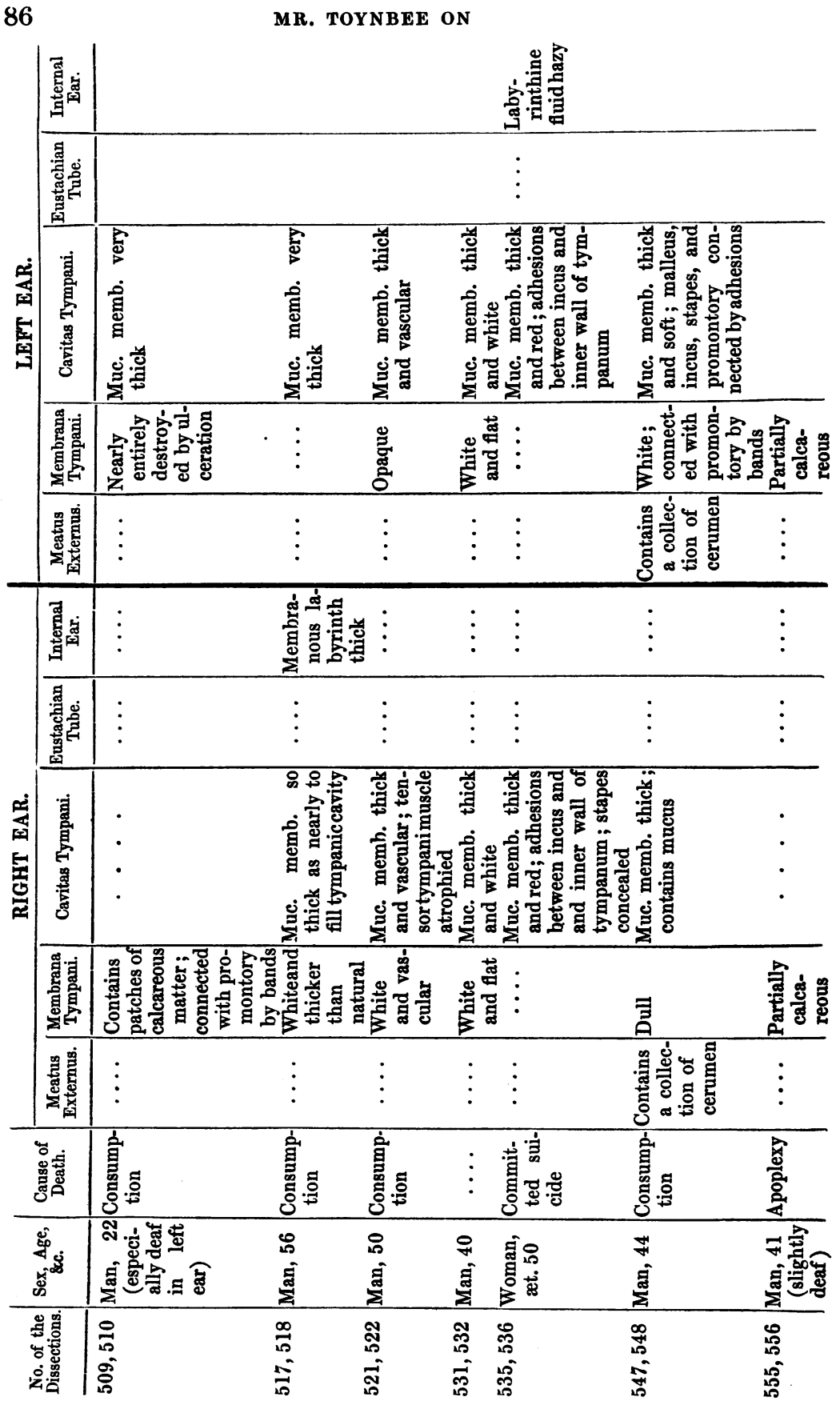




\begin{tabular}{|c|c|c|c|c|}
\hline 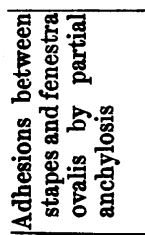 & 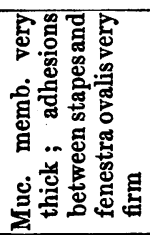 & 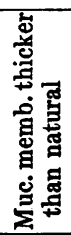 & 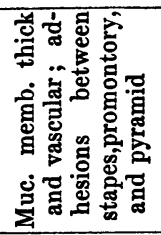 & 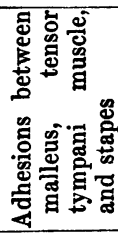 \\
\hline & 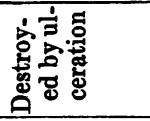 & $\vdots$ & $\vdots$ & : \\
\hline$\vdots$ & $\vdots$ & $\vdots$ & $\vdots$ & $\vdots$ \\
\hline 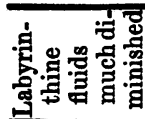 & $\vdots$ & $\vdots$ & $\vdots$ & $\vdots$ \\
\hline
\end{tabular}

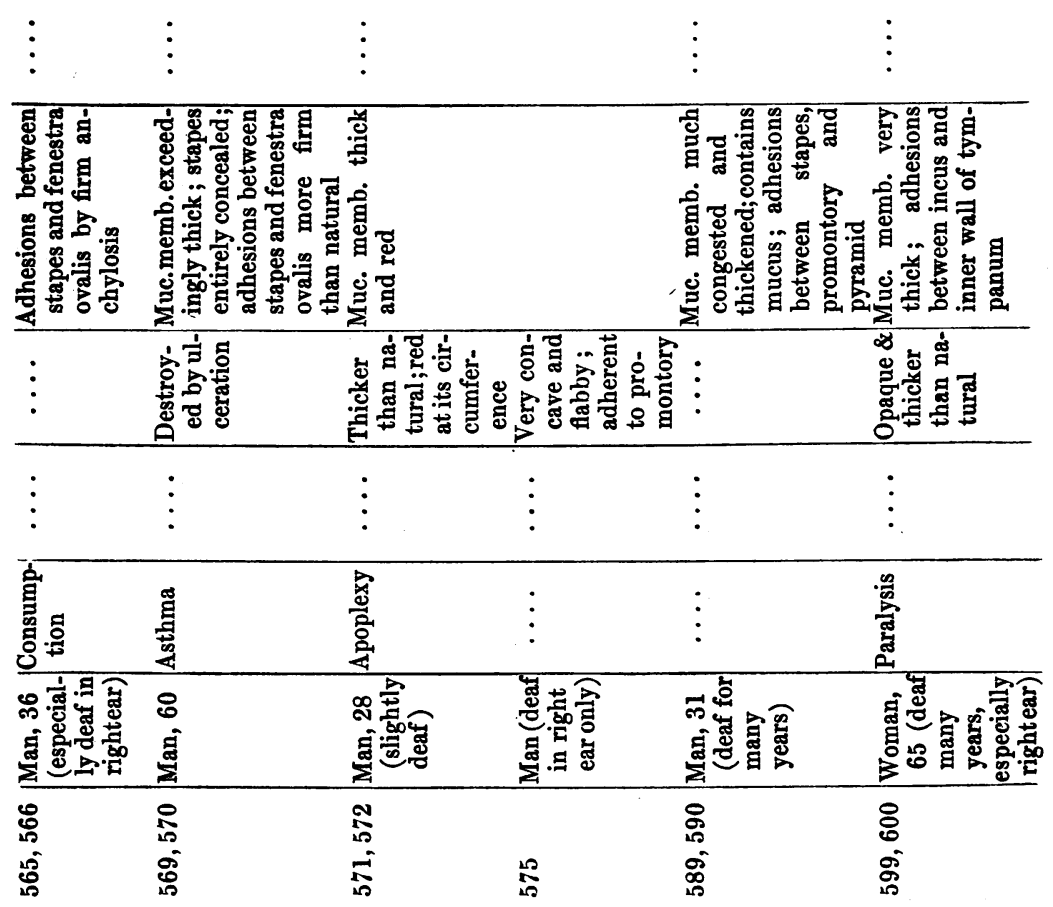




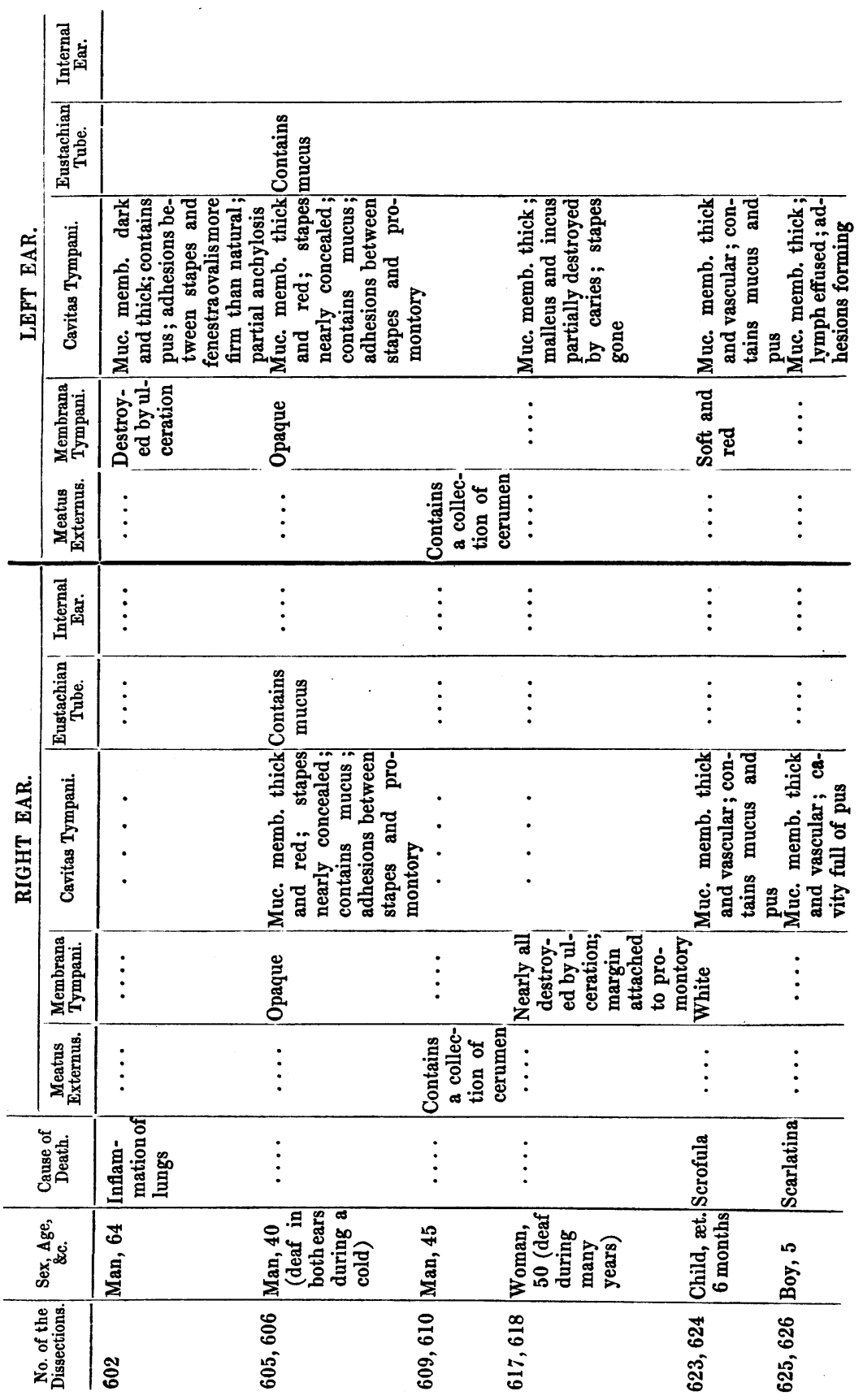



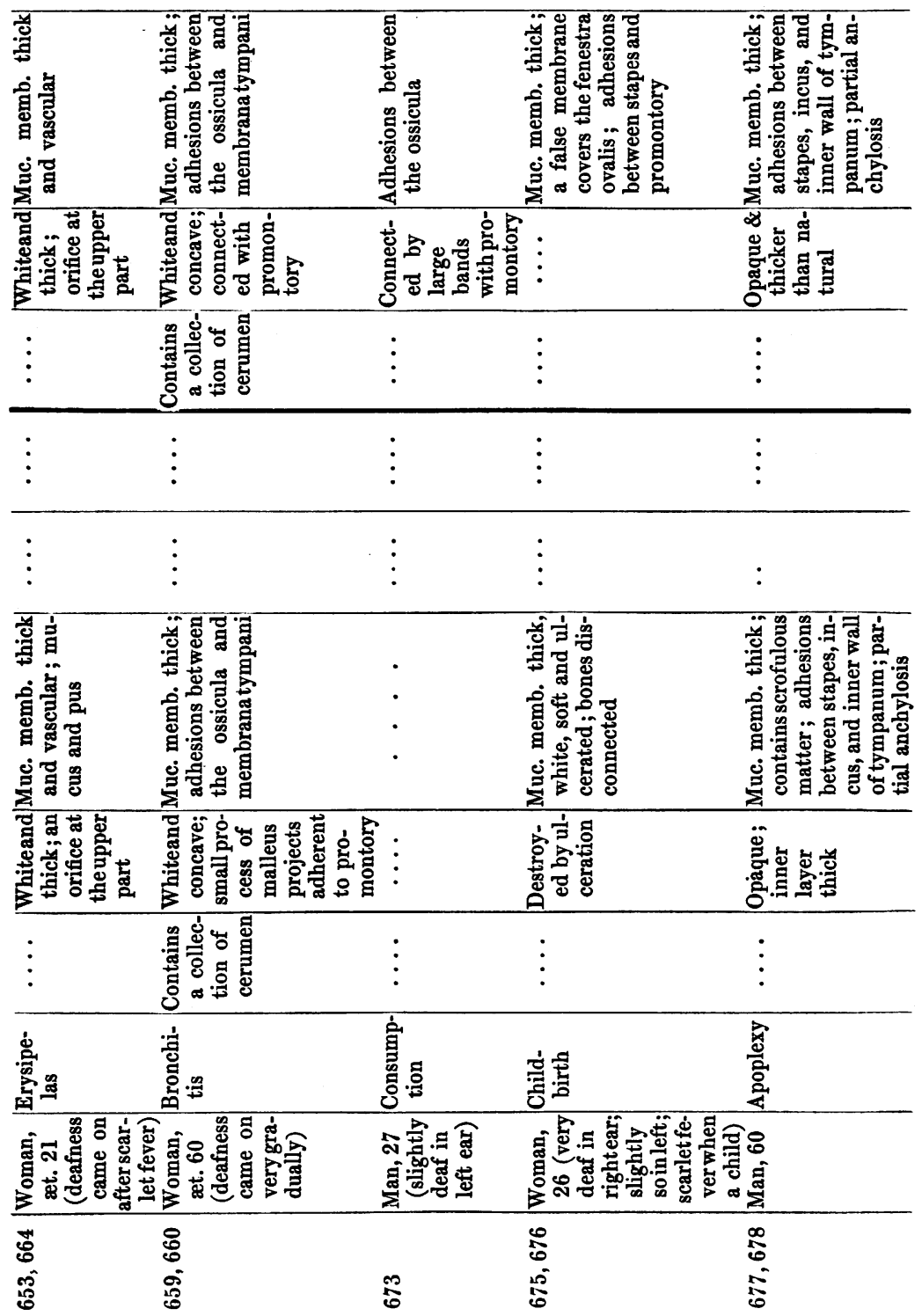


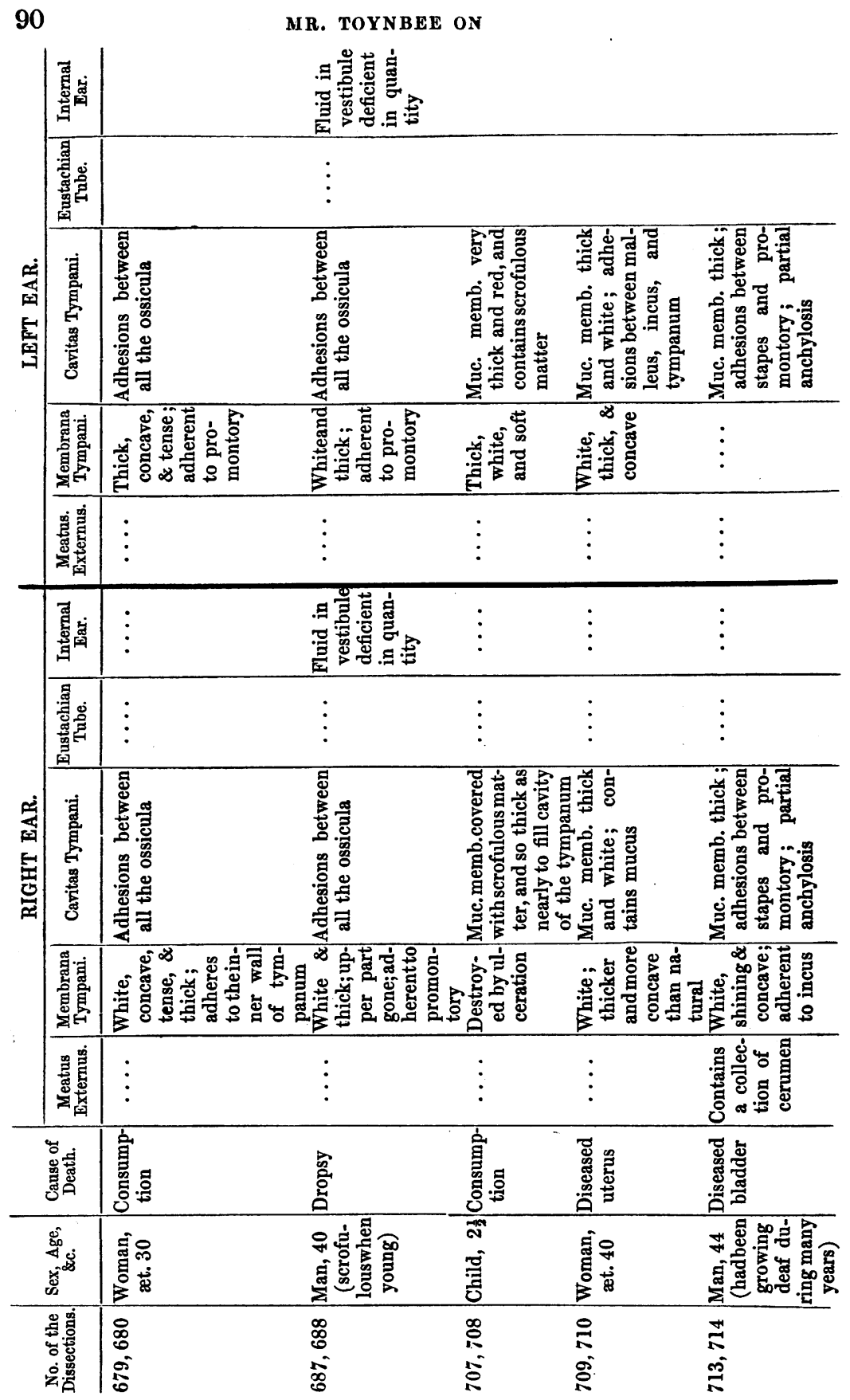



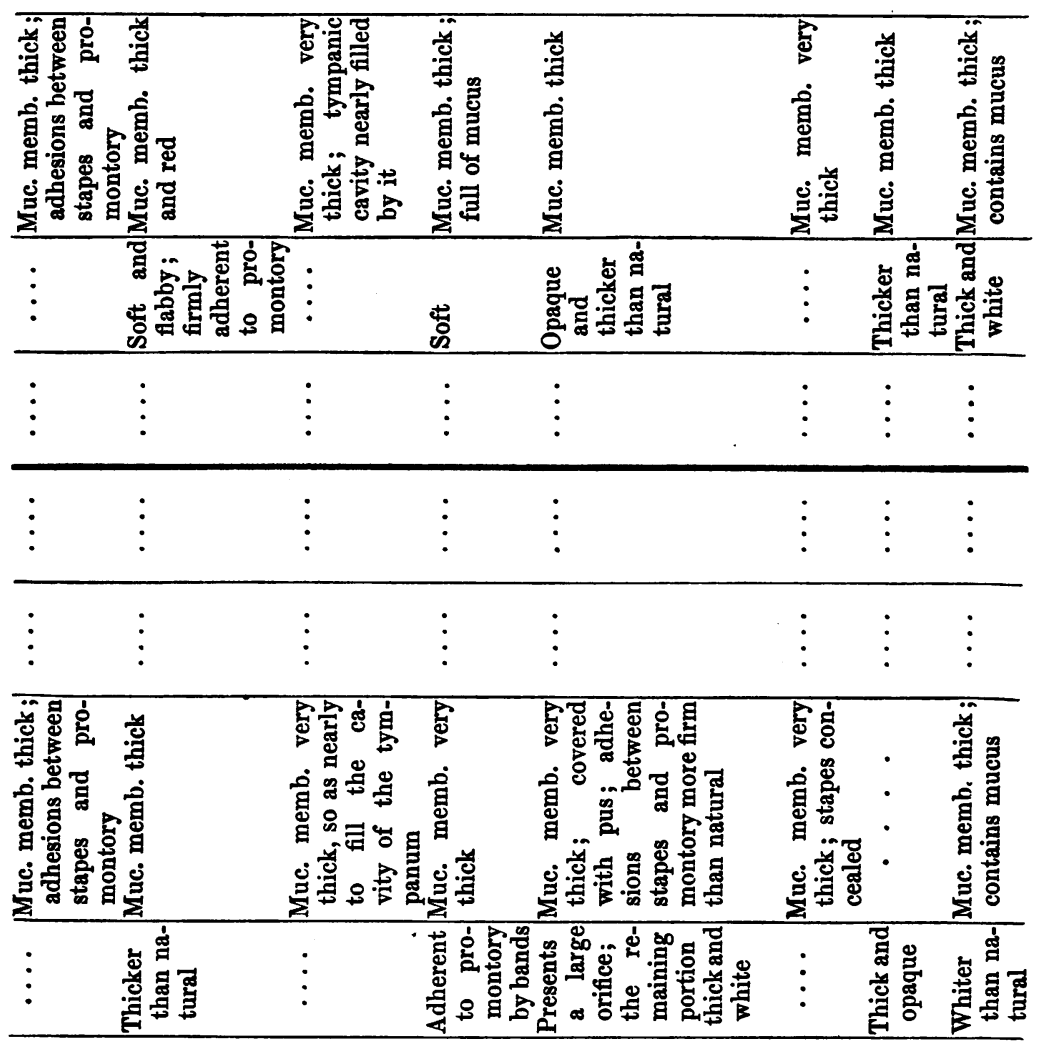

\begin{tabular}{|c|c|c|c|c|}
\hline 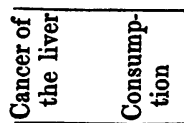 & 离 & 芯 & 惹 & 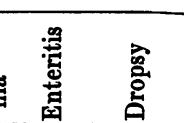 \\
\hline 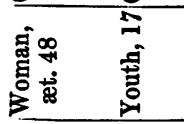 & 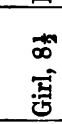 & $\vdots$ & 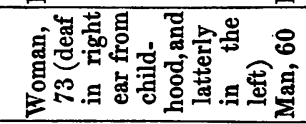 & 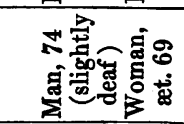 \\
\hline 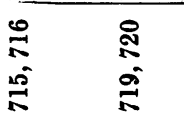 & 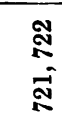 & 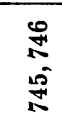 & 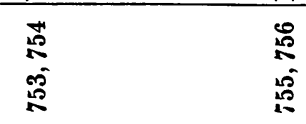 & 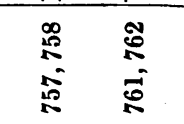 \\
\hline
\end{tabular}




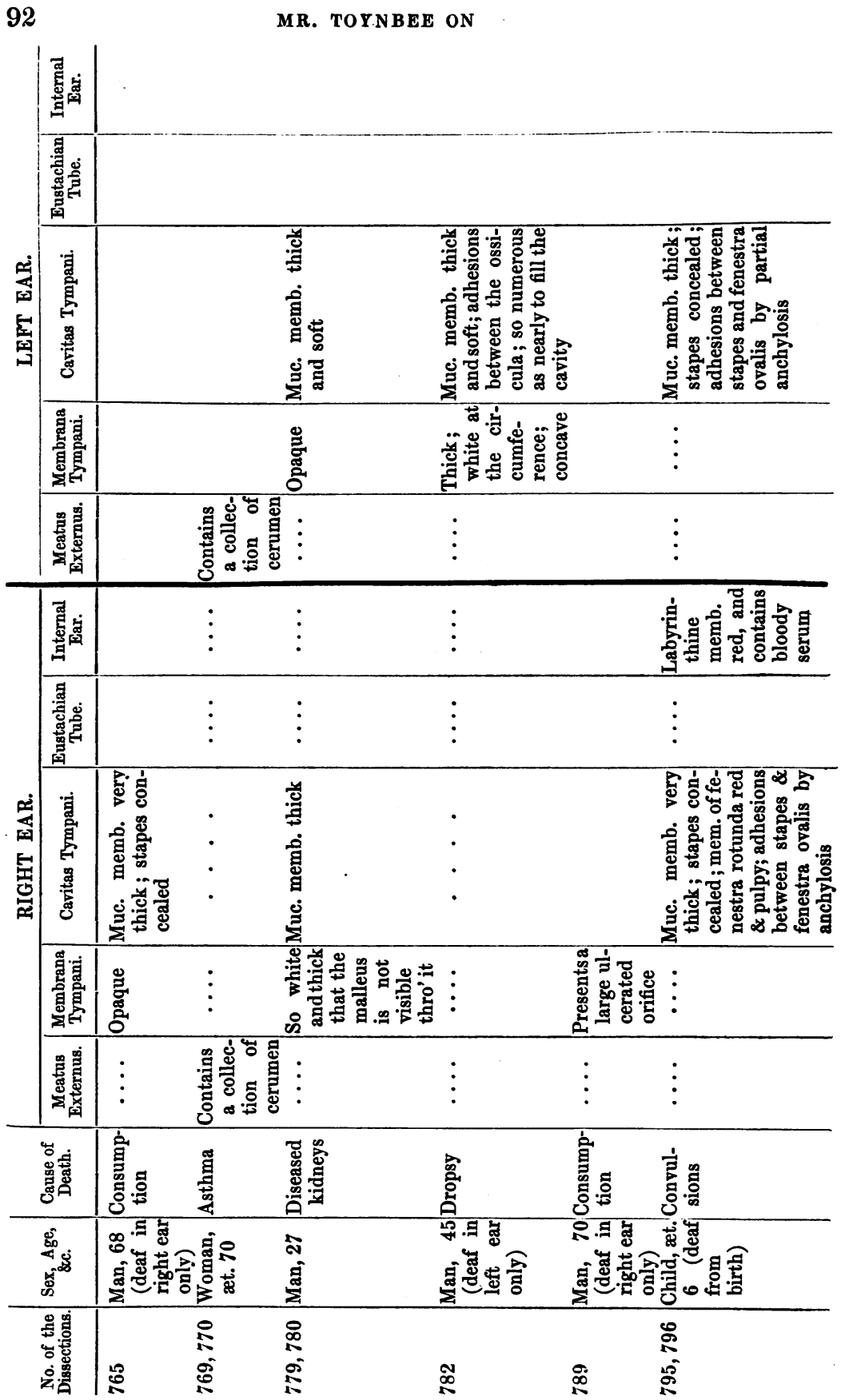


岁苛苞

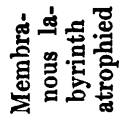

\begin{tabular}{|c|c|c|c|c|}
\hline 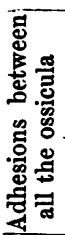 & 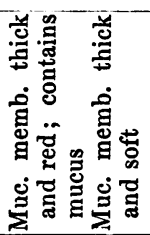 & 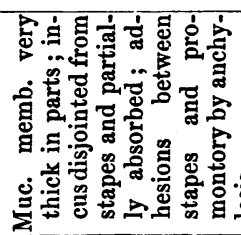 & 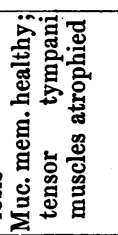 & 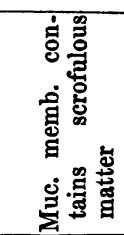 \\
\hline 音 & $\vdots \quad$ : & 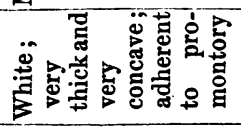 & 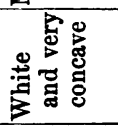 & - \\
\hline : & : & : & : & : \\
\hline : & : & : & : & : \\
\hline : & • & 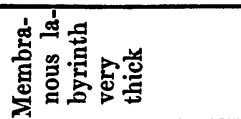 & 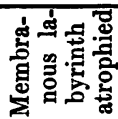 & \\
\hline
\end{tabular}

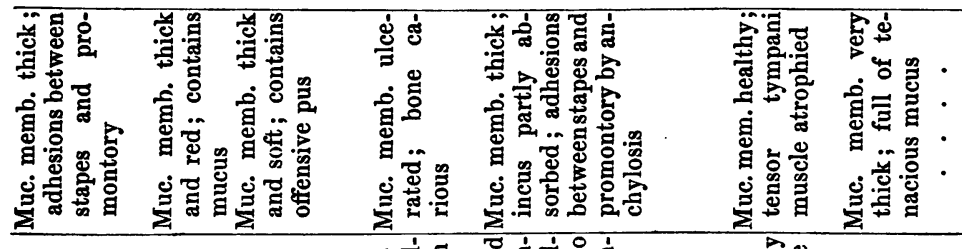

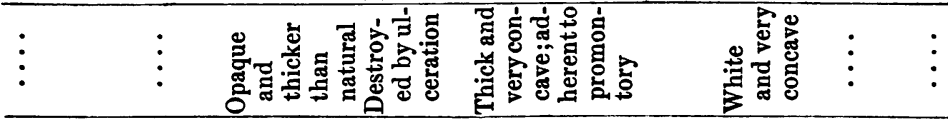

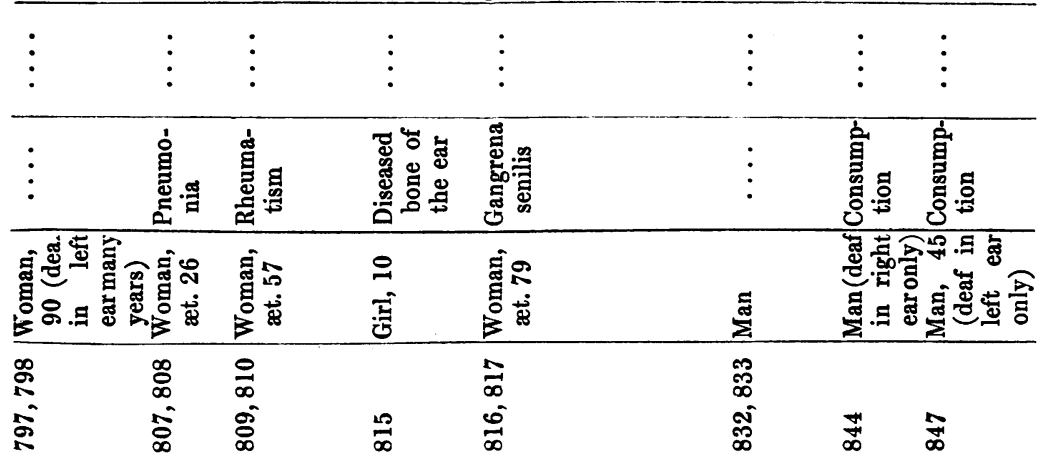




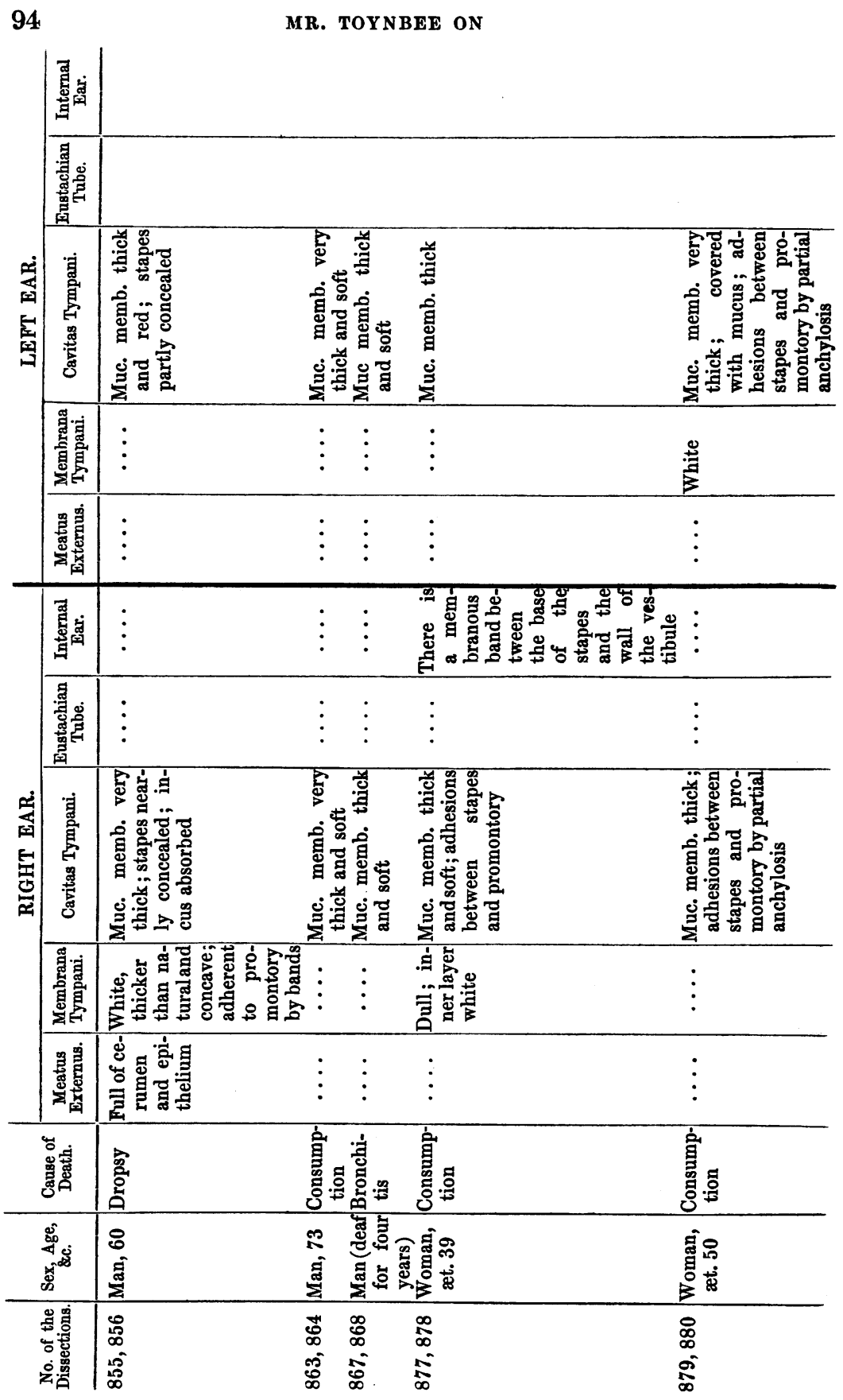




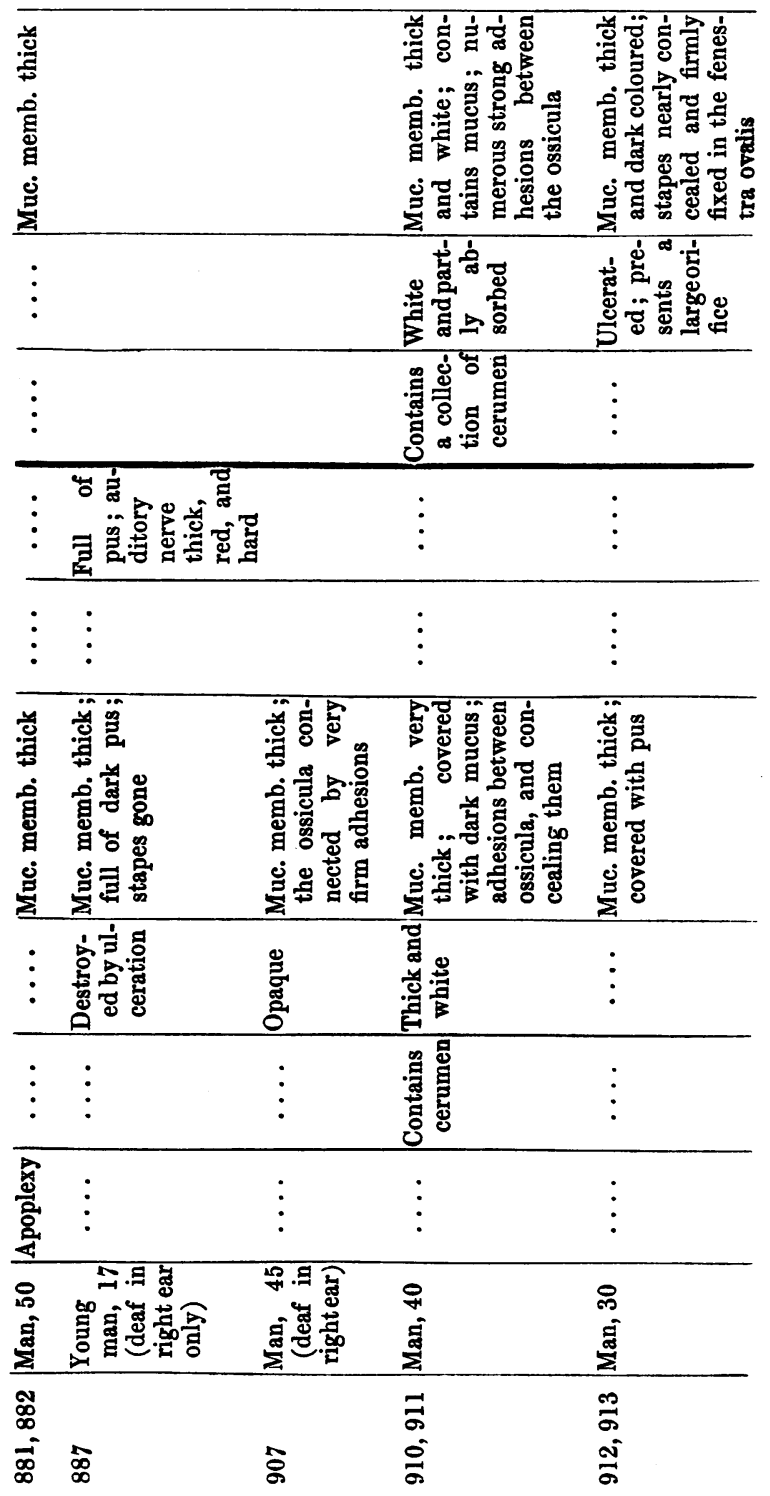




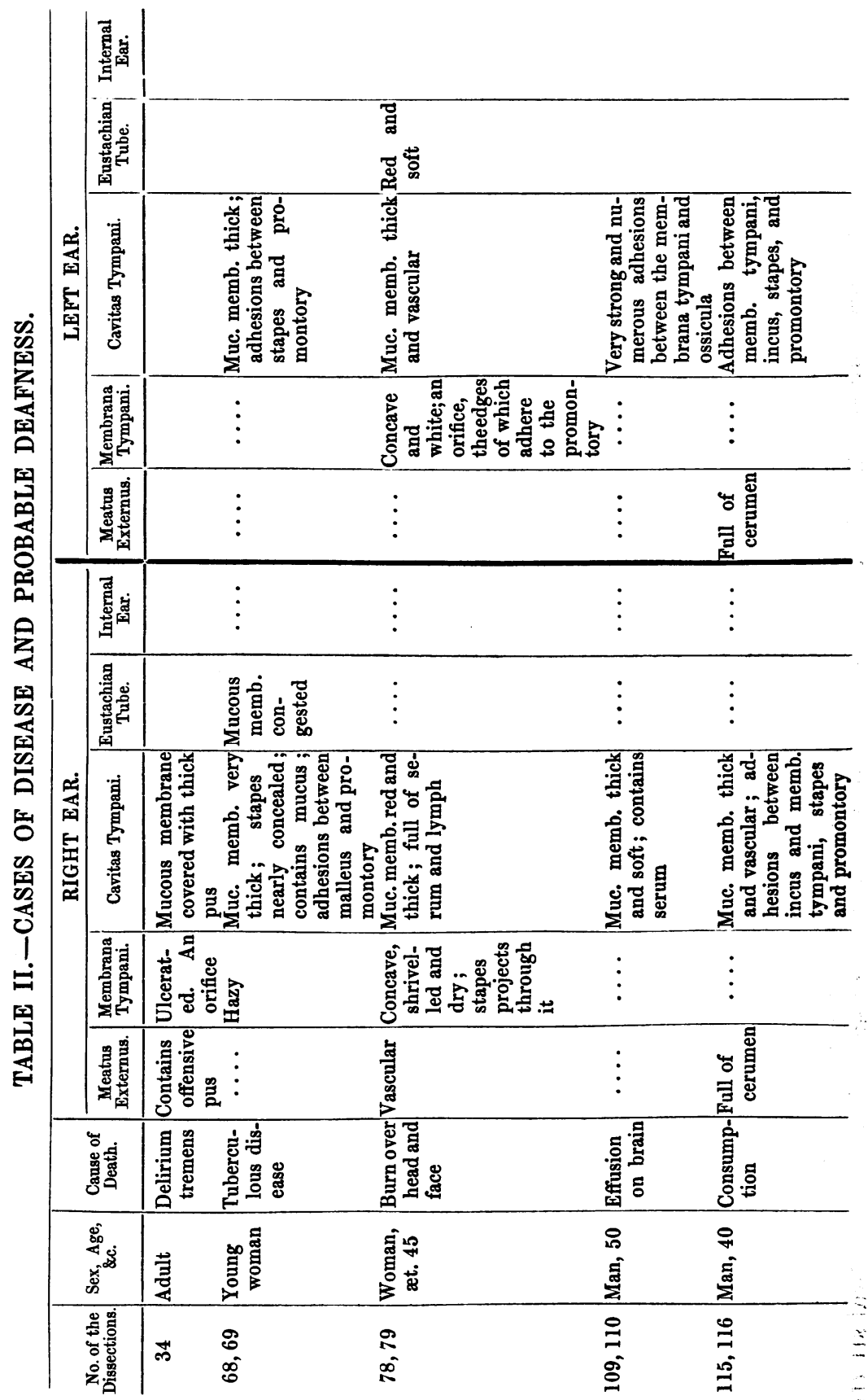




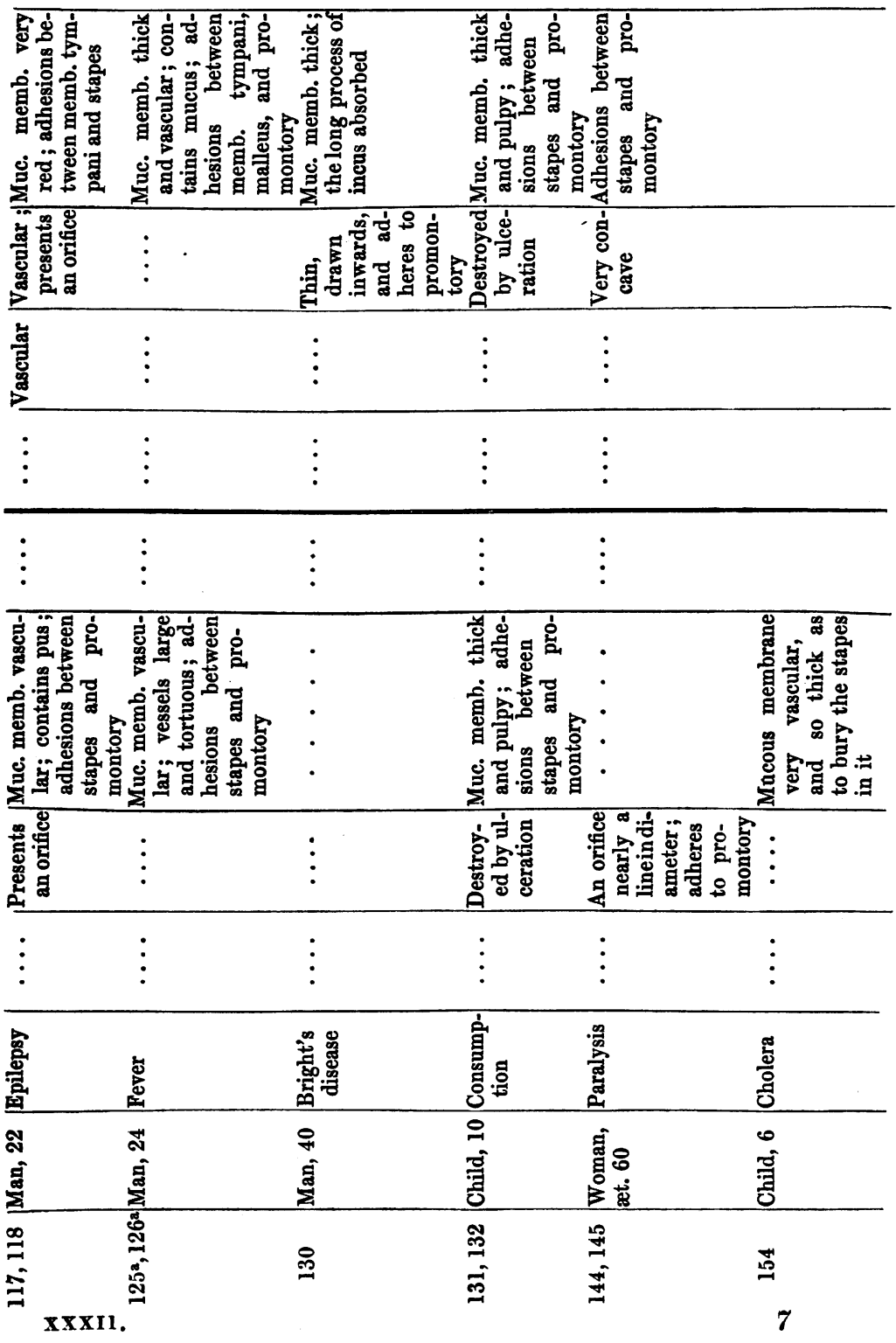




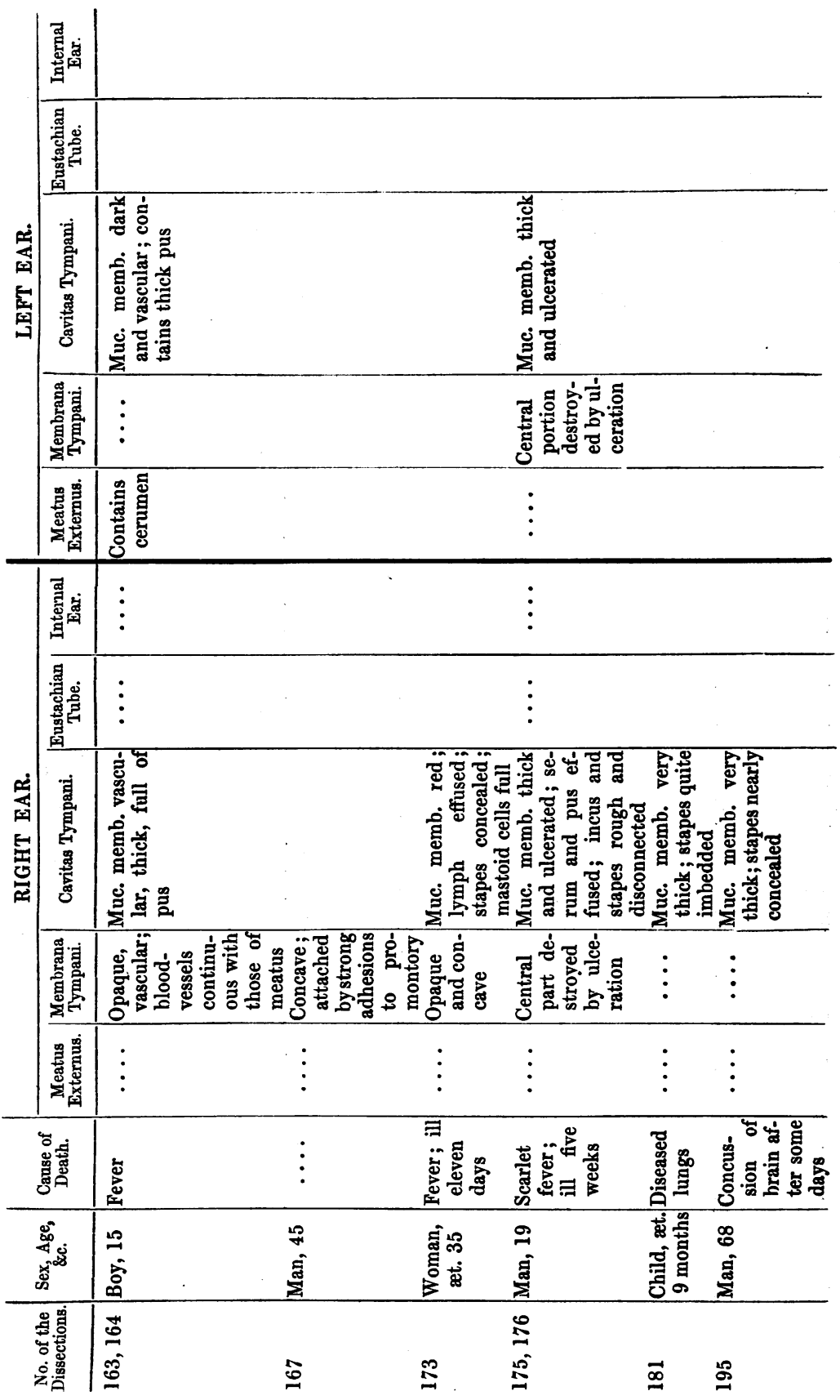




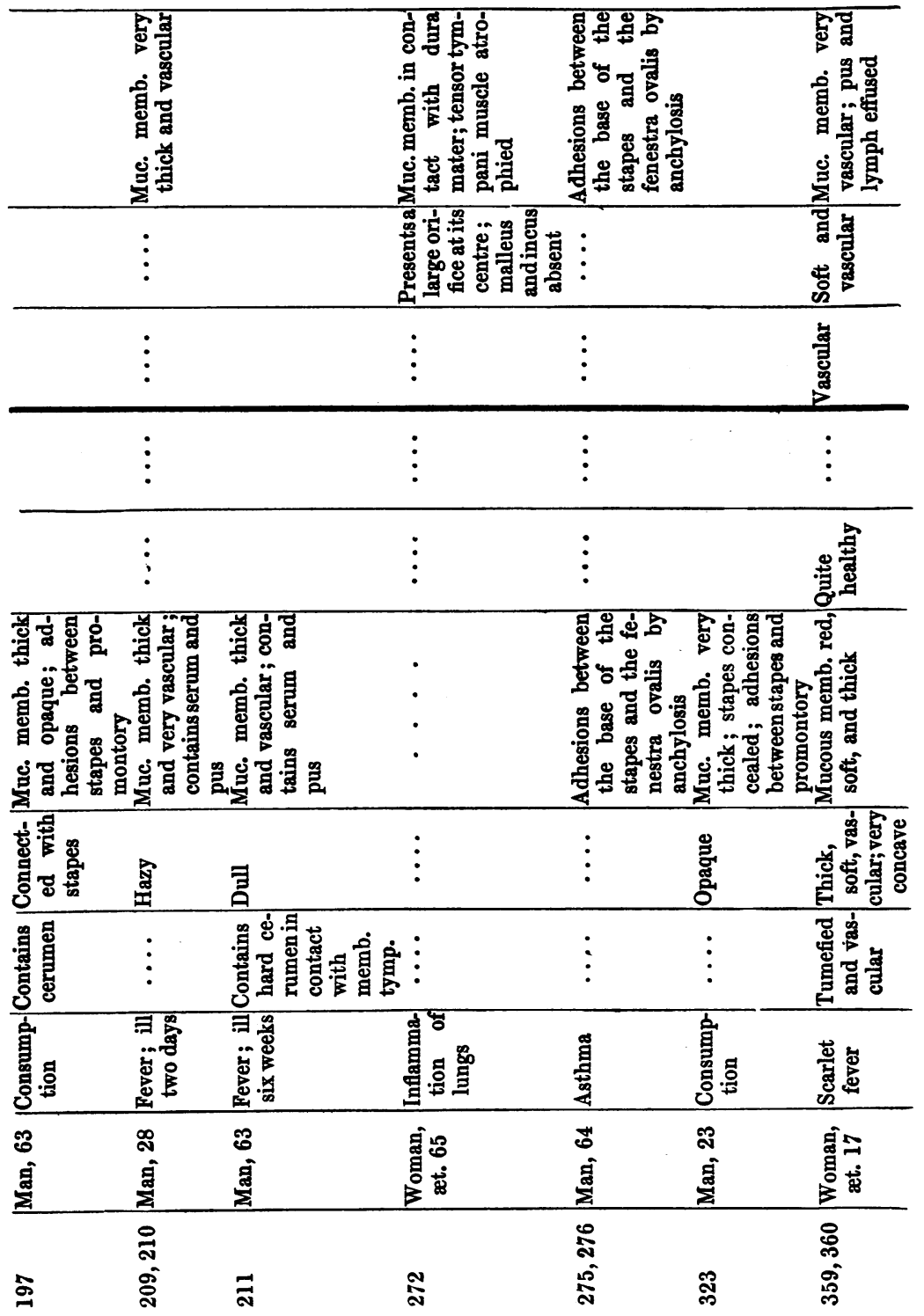




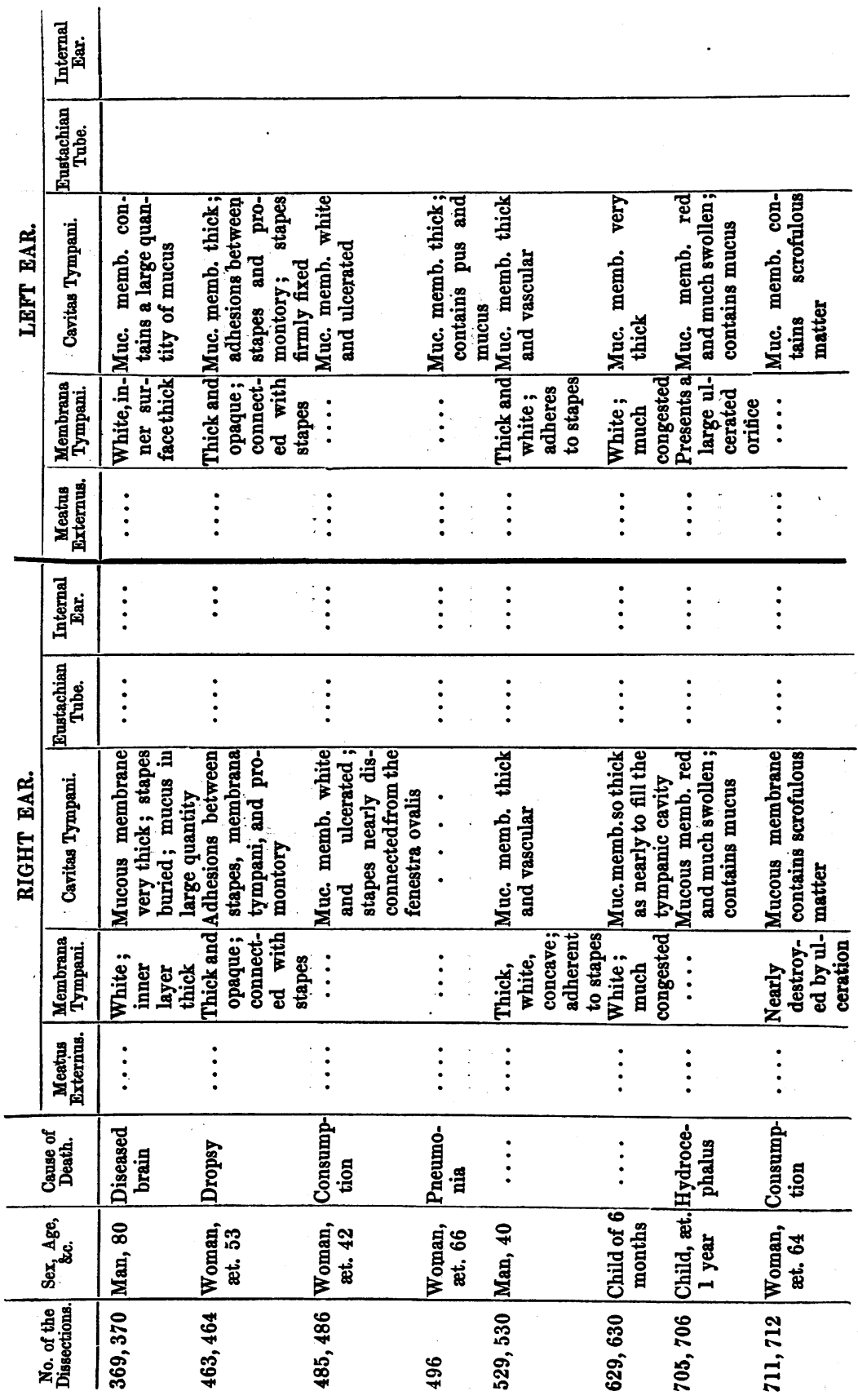




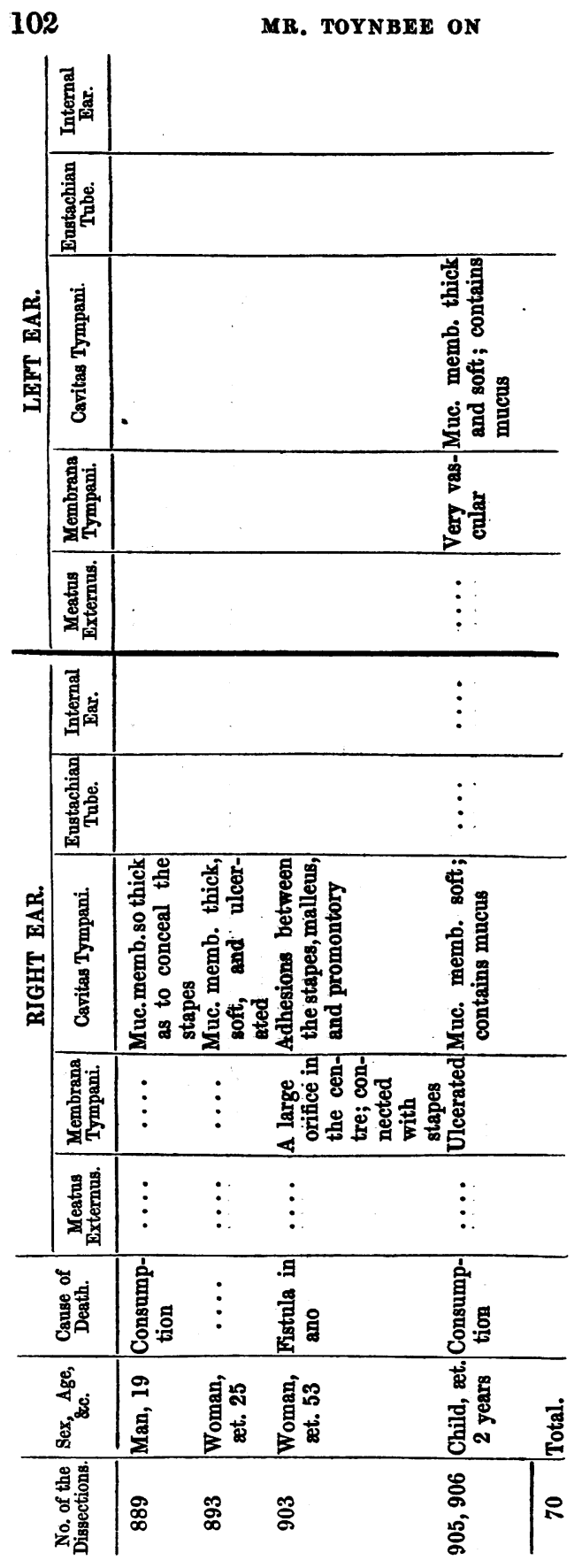


TABLE III.-CASES OF INCIPIENT DEAFNESS, 358.

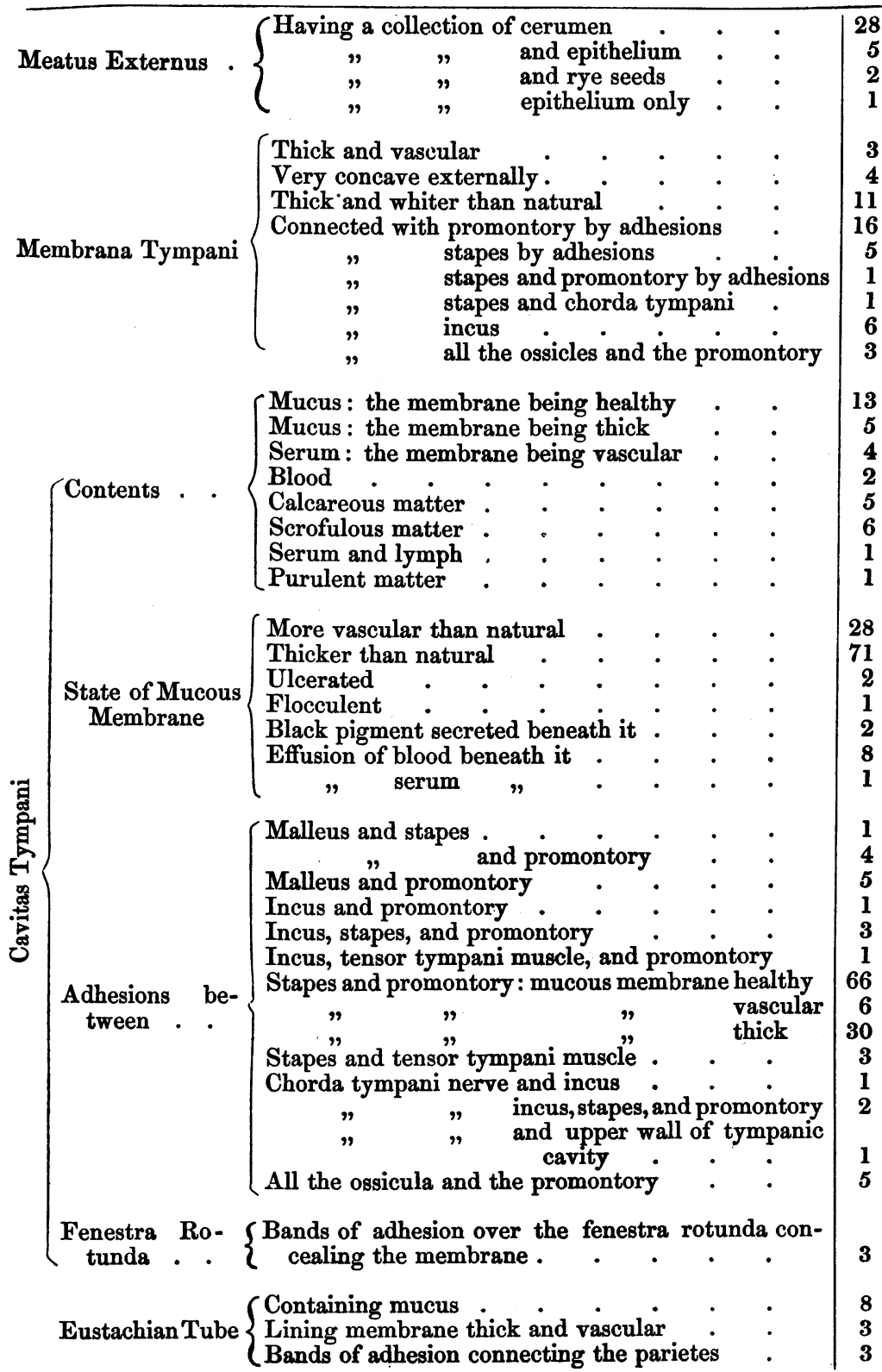


TABLE IV.

TABULAR ABSTRACT OF THE CONDITION OF THE 612 DISEASED EARS.

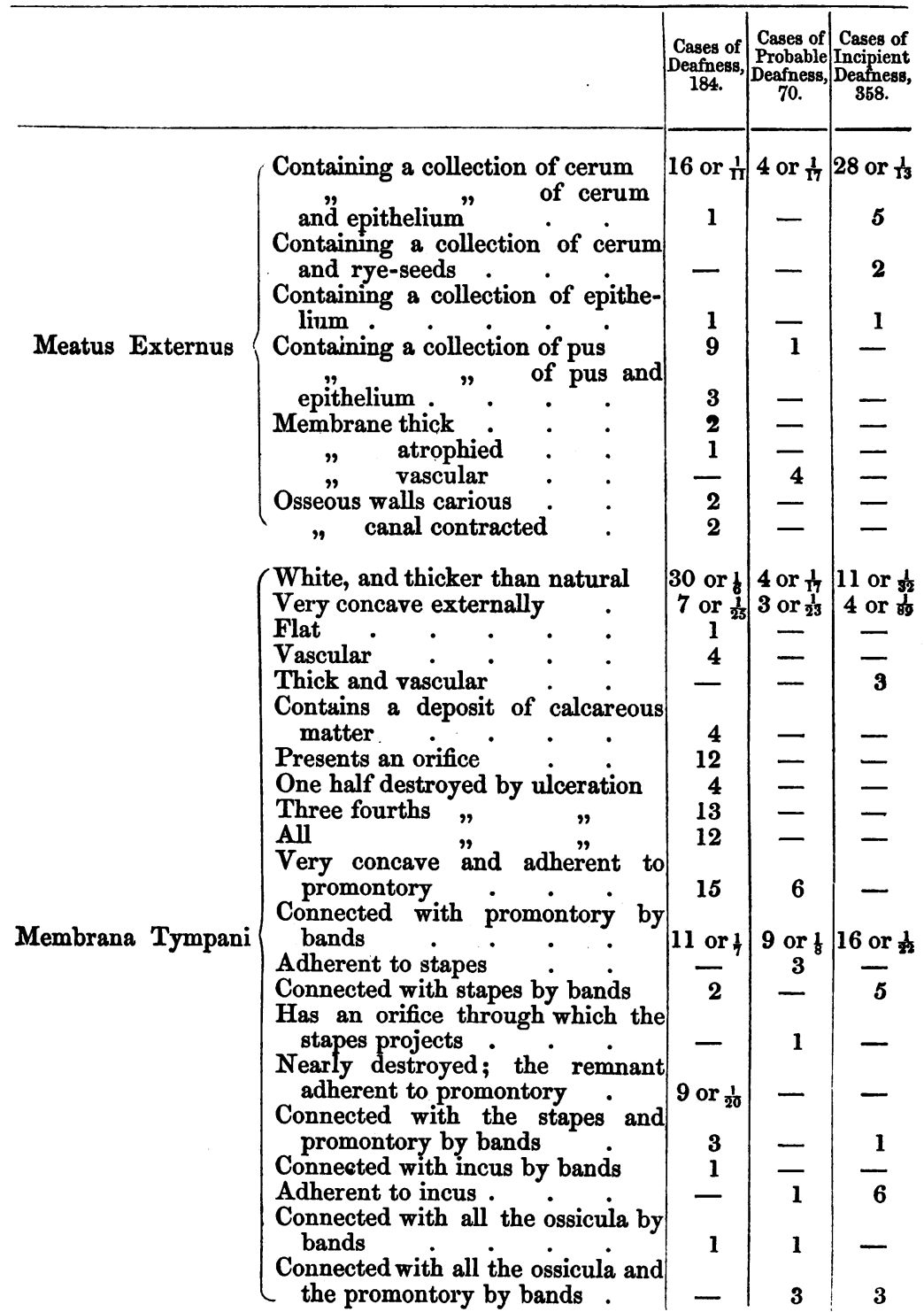




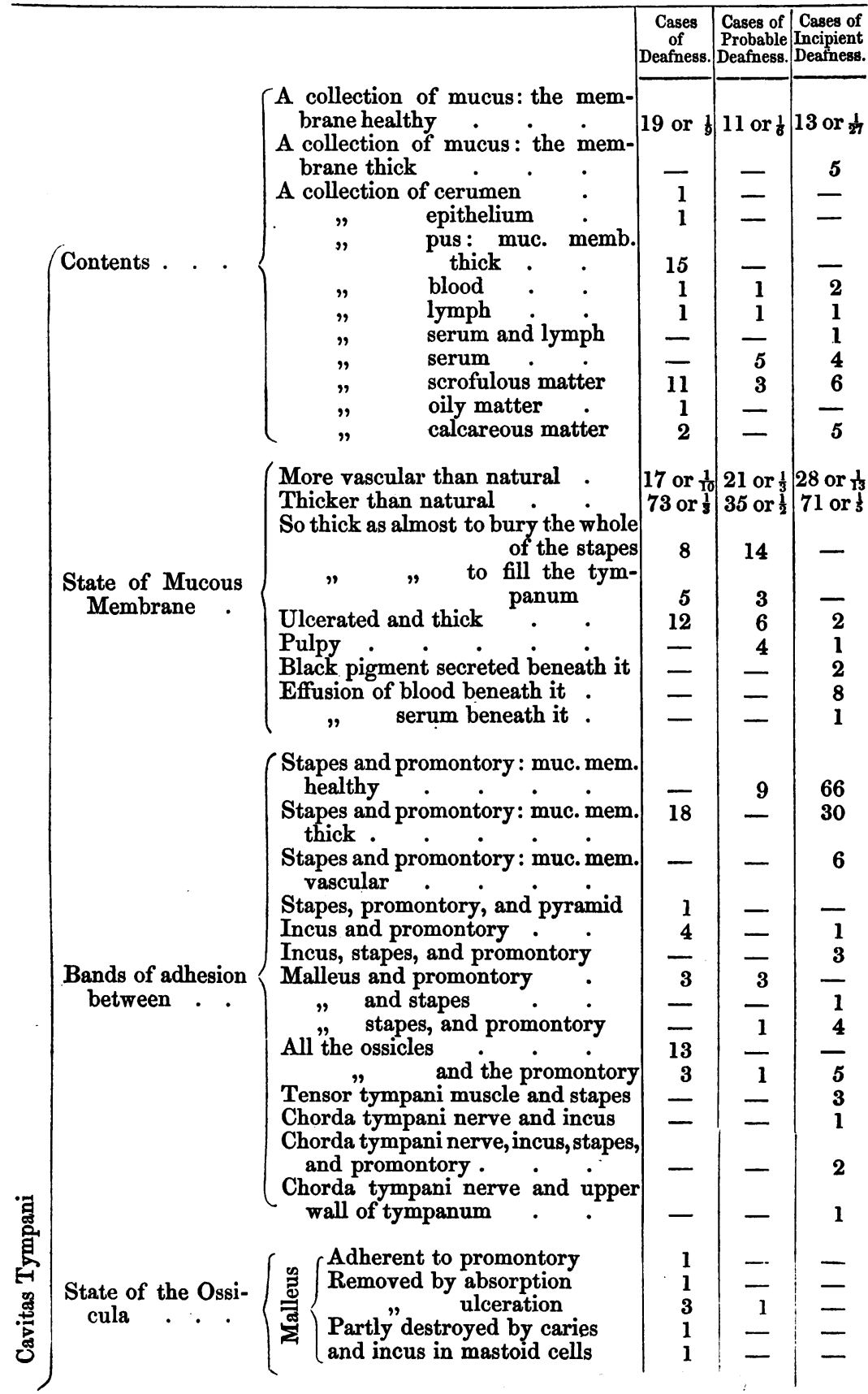




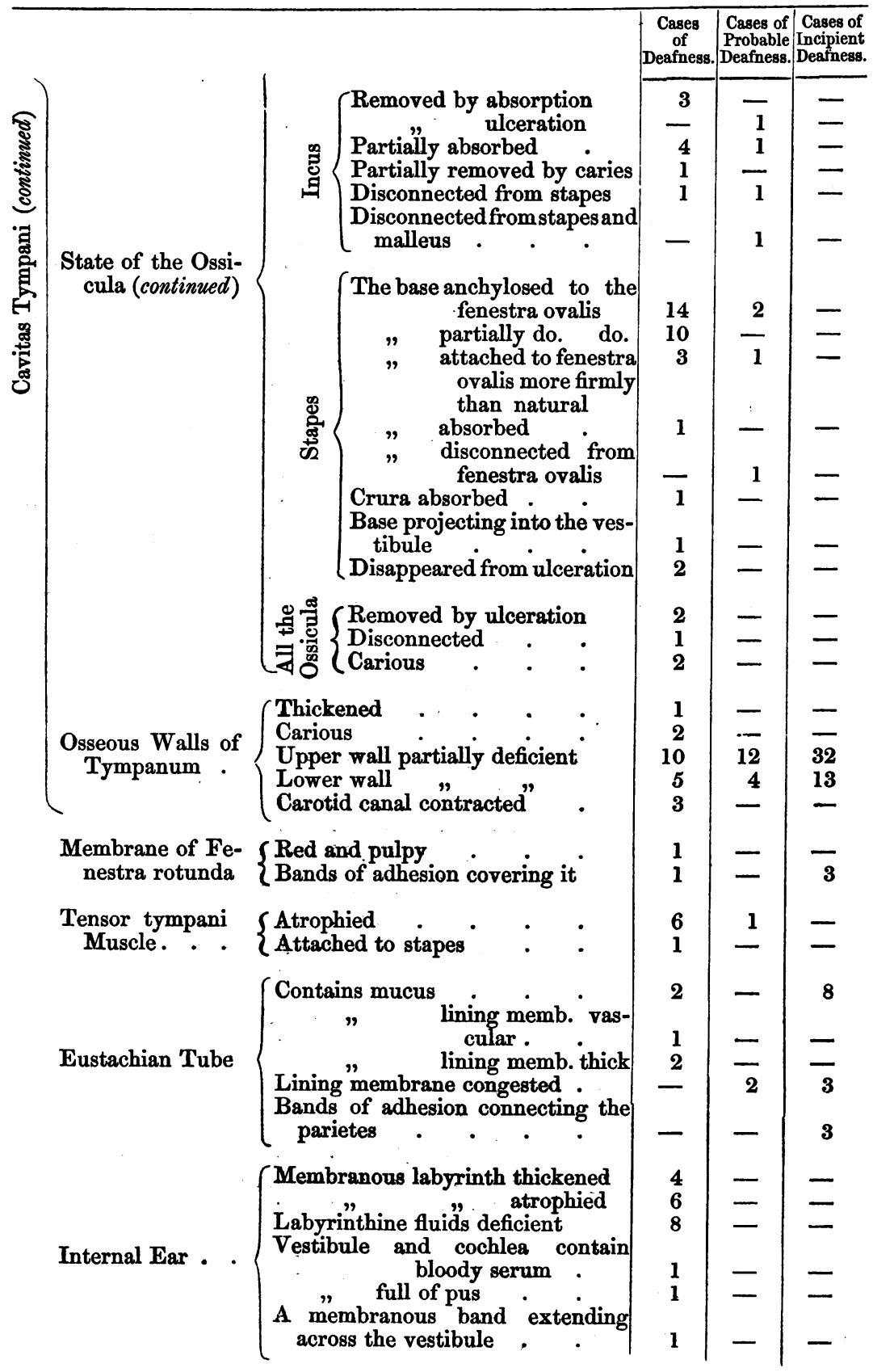

